\title{
Ground characterisation for PISA pile testing and analysis
}

\author{
LIDIJA ZDRAVKOVIĆ* ${ }^{*}$ RICHARD J. JARDINE*, DAVID M. G. TABORDA*, DAVID ABADIAS $\dagger$, \\ HARVEY J. BURD $\$$, BYRON W. BYRNE $\$$, KENNETH G. GAVIN§, GUY T. HOULSBY \\ TINGFA LIU*, CHRISTOPHER M. MARTIN\$, ROSS A. MCADAM \\ DAVID M. POTTS* JESPER SKOV GRETLUND** and EMIL USHEV ${ }^{*} \dagger$
}

\begin{abstract}
This paper is the first of a set of linked publications on the PISA Joint Industry Research Project, which was concerned with the development of improved design methods for monopile foundations in offshore wind applications. PISA involved large-scale pile tests in overconsolidated glacial till at Cowden, north-east England, and in dense, normally consolidated marine sand at Dunkirk, northern France. The paper presents the characterisation of the two sites, which was crucial to the design of the field experiments and advanced numerical modelling of the pile-soil interactions. The studies described, which had to be completed at an early stage of the PISA project, added new laboratory and field campaigns to historic investigations at both sites. They enabled an accurate description of soil behaviour from small strains to ultimate states to be derived, allowing analyses to be undertaken that captured both the serviceability and limit state behaviour of the test monopiles.
\end{abstract}

KEYWORDS: full-scale tests; in situ testing; laboratory tests; piles \& piling; site investigation; soil/structure interaction

\section{INTRODUCTION}

To meet the need for future energy supplies that are both sustainable and secure, there is significant current worldwide growth in the installation of renewable energy systems. Much of this growth is focused on the development of offshore wind farms. Since the costs of fabricating, transporting and installing the foundations for offshore wind turbine structures contribute significantly to overall project costs, financial incentives exist to employ foundation systems that minimise costs, while ensuring safe operation of the turbine support structure during its lifetime (typically 20-25 years).

Currently, monopiles are the preferred foundation type for most offshore wind turbines in relatively shallow waters - that is, less than about $35 \mathrm{~m}$ (see e.g. Kallehave et al., 2015).

Manuscript received 5 March 2018; revised manuscript accepted 4 July 2019. Published online ahead of print 15 November 2019.

Discussion on this paper closes on 1 March 2021, for further details see p. ii.

Published with permission by the ICE under the CC-BY 4.0 license. (http://creativecommons.org/licenses/by/4.0/)

$*$ Department of Civil and Environmental Engineering, Imperial College London, London, UK.

$\dagger$ Wood Thilsted Partners, London, UK; formerly Department of Civil and Environmental Engineering, Imperial College London, London, UK.

* Department of Engineering Science, University of Oxford, Oxford, UK.

$\S$ Delft University of Technology, Delft, the Netherlands; formerly School of Civil Engineering, University College Dublin, Dublin, Ireland.

|| Trinity College, Dublin, Ireland; formerly School of Civil Engineering, University College Dublin, Dublin, Ireland.

I Wood Thilsted Partners, London, UK; formerly Ørsted Wind Power, London, UK.

** Ørsted Wind Power, Copenhagen, Denmark.

$\dagger$ Arup, London, UK; formerly Department of Civil and Environmental Engineering, Imperial College London, London, UK.
Monopiles for offshore wind turbines are subjected to lateral loading from tidal, wave and wind action, as well as dynamic loads associated with 'rotor stop' conditions or faults in the turbine or drivetrain. Design procedures for monopile foundations typically employ the well-established ' $p-y$ ' method (API, 2010; DNVGL, 2016), a numerical approach in which the foundation is modelled as an embedded beam with the soil response represented by empirically based non-linear ' $p-y$ ' curves. In the analysis, the simplifying Winkler assumption is adopted - that is, the soil reaction, $p$, acting at a particular point is determined solely by the soil displacement, $y$, at that point.

This is a reasonably simple and fast calculation method, and therefore preferred by industry for the large number of repeat calculations required for a typical wind farm site. However, it was developed for long and slender piles typically employed in the oil and gas industry: piles of this sort, with a relatively large length-to-diameter ratio $(L / D)$, typically respond in a flexible manner to lateral loads. Monopiles for offshore wind turbines, however, usually have relatively low $L / D$ ratios (between about 2 and 6) and typically deform almost rigidly under lateral loading. The $p-y$ method has been shown to be systematically inaccurate for the design of large-diameter and short wind turbine monopiles (Kallehave et al., 2015). Questions have therefore arisen (e.g. Jeanjean, 2009; Klinkvort et al., 2016) about the extent to which current forms of the $p-y$ method provide a satisfactory basis for offshore monopile design. As the pile $L / D$ ratio is reduced, the $p-y$ method appears to underestimate both the strength and stiffness of laterally loaded monopiles (e.g. Alderlieste et al., 2011; Doherty \& Gavin, 2012): this perceived phenomenon is sometimes referred to as a 'diameter effect'.

As a result, there is an industrial imperative to improve design methodology. The PISA (Pile-Soil Analysis) joint industry project (JIP), led by Carbon Trust and Ørsted (formerly DONG Energy), aimed to meet this objective through a 30 month study, starting in August 2013, that involved an academic work group comprising Oxford University, Imperial College London and University College Dublin. Funding was provided by the project 
partners listed in the Acknowledgements, through the Carbon Trust's offshore wind accelerator programme. The overall project structure is summarised in the Appendix. The project was concerned particularly with the design of monopiles in North Sea waters, and consisted of three interlinked activities

(a) reduced-scale field testing of monopiles at two representative sites (an overconsolidated clay till site at Cowden in the UK and a dense sand site at Dunkirk in France)

(b) developing three-dimensional (3D) finite-element (FE) models to represent the performance of each of the test monopiles

(c) developing a new approach for monopile design (the 'PISA design model') consisting of an enhanced form of the $p-y$ method.

The project was concerned principally with the design of piles for monotonic loading conditions, although some strain-rate and cyclic field testing was also conducted.

The scope of the PISA study, and some preliminary results, are summarised in conference publications (e.g. Byrne et al., 2015a, 2015b, 2017; Zdravkovic et al., 2015).

This paper is the first in a series of linked publications comprehensively describing the PISA project and providing an overview of the PISA field testing programme, including a description of the site selection process and a summary of the site investigation campaign and soil characterisation procedure. Burd et al. (2019) describe the specification of the field tests, together with a description of the experimental set-up and the procedures that were employed to collect and process the test data and to check the consistency and performance of the instrumentation. Full accounts of the field test data are given in the papers by Byrne et al. (2019) and McAdam et al. (2019) for the Cowden and Dunkirk sites, respectively. Two further publications, by Zdravković et al. (2019) and Taborda et al. (2019), describe the 3D FE modelling that was developed to support the inter-pretation of the field tests and the development of the PISA design model (Byrne et al., 2017). Further publications are planned in which the PISA design model will be described.

In the PISA design model, consistent with the $p-y$ method, the pile is modelled as an embedded beam. Soil reactions are applied to the pile using pre-determined non-linear functions referred to as 'soil reaction curves'. In the $p-y$ method (in the form specified in the API (2010) and DNVGL (2016) standards) the soil reaction consists solely of a distributed lateral load. In the PISA design model (illustrated in Fig. 1), however, this approach is extended to include additional soil reactions: a distributed moment, $m$, applied along the length of the pile, and a horizontal force, $H_{\mathrm{B}}$, and moment, $M_{\mathrm{B}}$, both applied at the pile base. These extensions follow work by Davidson (1982), Lam \& Martin (1986), Gerolymos \& Gazetas (2006) and Lam (2013) for the design of caisson and drilled pier foundations for onshore applications. Consistent with this previous work, it is hypothesised that any observed diameter effect is, in fact, an indication that the $p-y$ modelling approach omits certain key pile-soil interaction mechanisms; the additional soil reactions employed in the PISA design model provide a rational basis for developing models in which unrealistic effects relating to the pile diameter are absent.

Appropriate functions for the soil reaction curves in the PISA design model need to be selected and calibrated. In the original development of the $p-y$ method, $p-y$ curves were determined directly from field measurements on a set of test piles. This experimental approach cannot be used in the current work for three principal reasons: $(a)$ the field testing conducted in the PISA study is based on the use of reduced-scale monopiles; uncertainties exist on the extent to which the data can be reliably extrapolated to full-scale; $(b)$ it is impractical to devise instrumentation systems that are capable of resolving the four separate soil reaction components that form the model; $(c)$ appropriate soil reaction curves for a particular design scenario may, to a certain extent, depend on specific aspects of the site

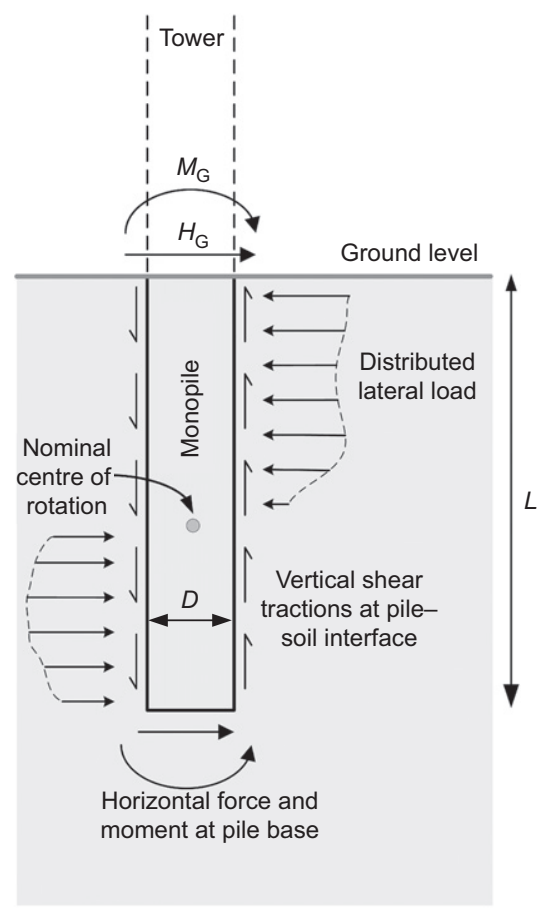

(a)

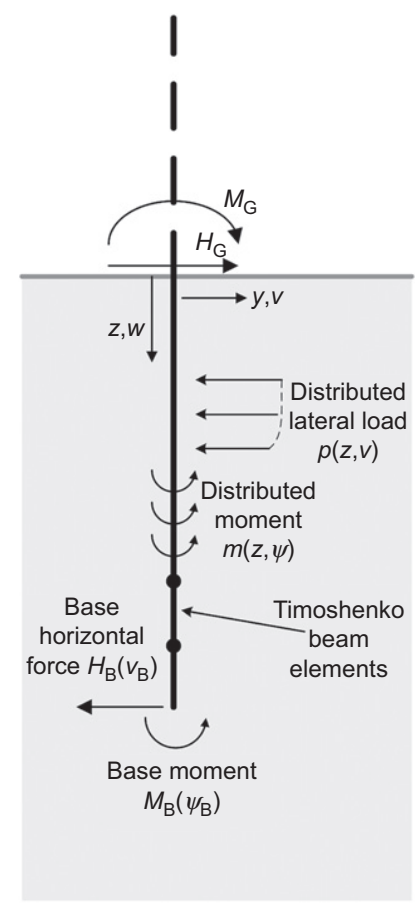

(b)

Fig. 1. The PISA design model 
(e.g. details on variations of strength with depth and soil layering). It would be impractical to embark on a field testing campaign to investigate all of the likely variations.

The alternative approach used in the PISA study to calibrate the design model is illustrated in Fig. 2. Field tests were conducted at two test sites (Cowden and Dunkirk). These tests were designed to provide data on pile behaviour for soil conditions, pile length-to-diameter ratios and loading configurations that are broadly representative of typical design conditions, but the tests do not span the entire design space. Separately, an advanced 3D FE model was established for each test site, using bespoke site investigation and advanced numerical modelling. These FE analyses were performed before the field tests were completed, with the purpose of aiding the design of the field testing programme and, subsequently, for checking the accuracy of the FE model by comparison with the field test data (a process indicated as 'validation' in Fig. 2). Having found that the 3D FE model provided an acceptable representation of the field tests, it was then used to conduct separate calibration analyses (extending the range of soil, pile and loading parameters that were considered in the field tests) to determine appropriate forms of soil reaction curves for implementing in the PISA design model. The resulting design model provides predictions that are comparable in accuracy to the 3D FE analyses on which it is based, but with a much faster computation time. The current form of the design model is suitable for monotonic loading only, which was the central focus for PISA. Since current cyclic loading design methods are typically based on the monotonic loading response, it is important that the monotonic response can be accurately captured and predicted before the method is extended to cyclic loading.

\section{SITE SELECTION}

The sites selected for testing were the Cowden overconsolidated low-plasticity glacial clay till site in north-east England, and the Dunkirk normally consolidated dense sand location in northern France. Both provide ground profiles representative of multiple North Sea windfarm sites and have been used in previous piling and characterisation research. Earlier studies by Jardine (1985), Lehane (1992), Powell \& Butcher (2003), Chow (1997), Kuwano (1999) and Sim et al. (2013) provided particularly useful information. Fig. 3(a) shows the location of the PISA test site at Cowden with respect to the historic testing area, while Fig. 3(b) shows the corresponding disposition for the PISA Dunkirk site. New project-specific field and laboratory testing was conducted to address some specific requirements of the PISA 3D FE analyses. Key aims were to address the non-linear smallstrain and ultimate shear strength behaviour of the soil within an overarching critical state framework. These features are vital to capturing both the operational and ultimate capacity behaviour of monopile foundations. Consequently, investigations of site geology were not the subject of the PISA study as this was available from the historic literature, in particular

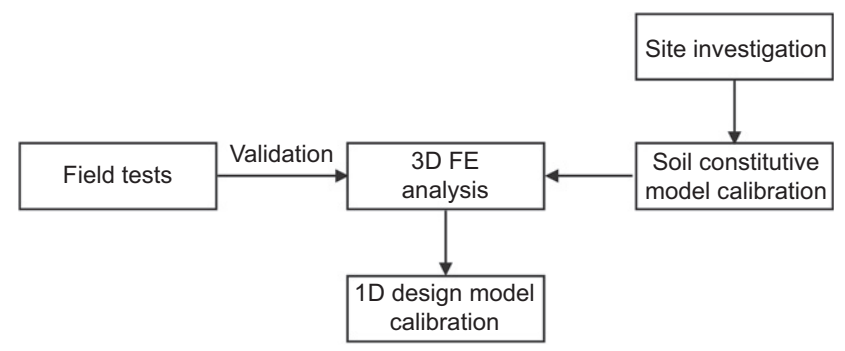

Fig. 2. Design model development process adopted in PISA

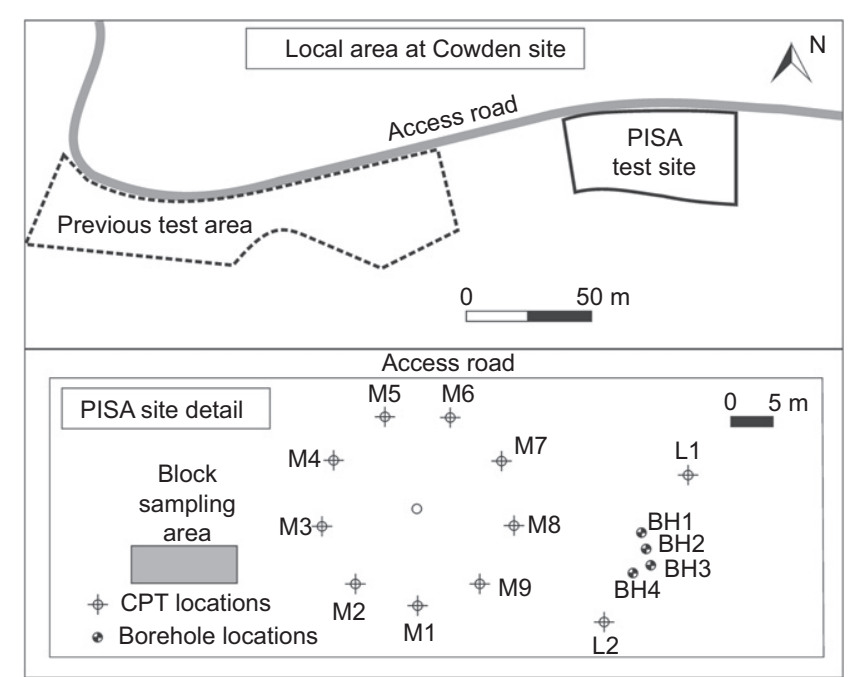

(a)

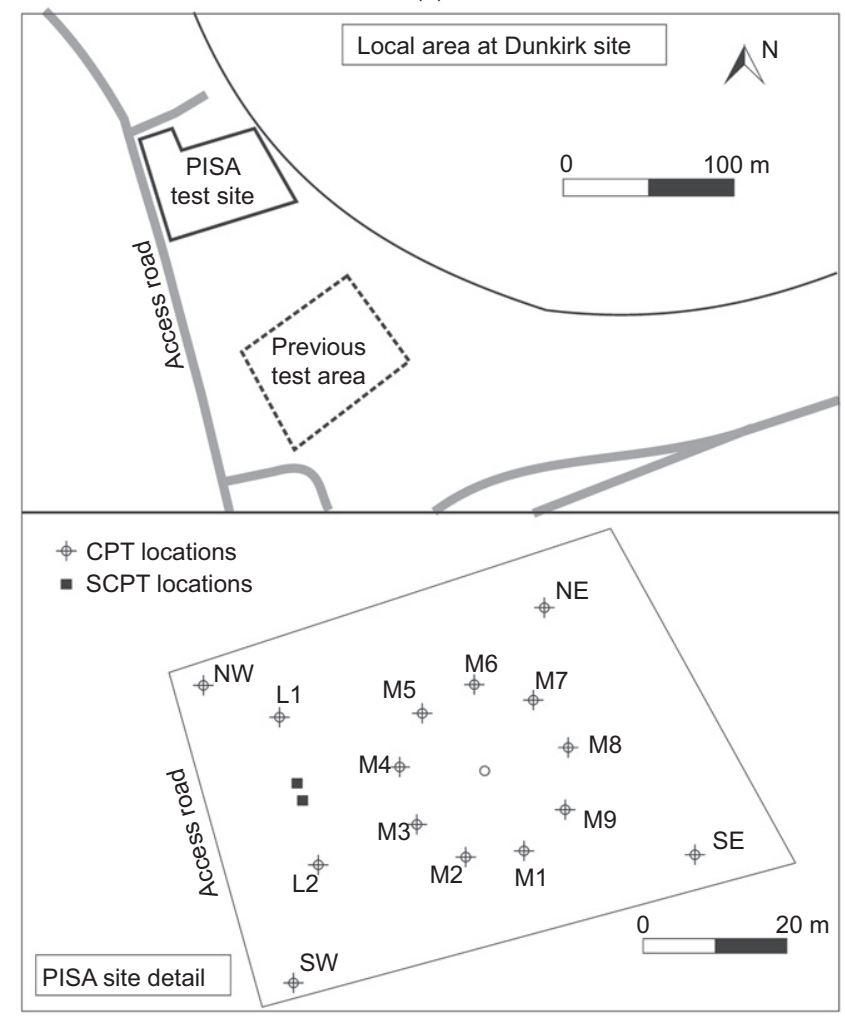

(b)

Fig. 3. (a) Cowden site and (b) Dunkirk site: 'Local area' showing the extent of the previous and PISA test sites; 'PISA site detail' showing in situ test locations

Powell \& Butcher (2003) for the site at Cowden, and Chow (1997) for the site at Dunkirk.

This paper summarises how the existing and new experimental studies were integrated to develop representative ground models that subsequently enabled derivation of appropriate parameters for the constitutive modelling of the two soils (Taborda et al., 2019; Zdravković et al., 2019) and for the design of pile testing procedures in the field (Byrne et al., 2019; McAdam et al., 2019).

\section{COWDEN SITE}

Ground conditions

Powell \& Butcher (2003) summarise the ground conditions at Cowden, synthesising several studies from the 1980s and 1990s that were conducted over a much larger site 
area (Fig. 3(a)), around $100 \mathrm{~m}$ from the PISA test location. They report that the ground profile comprises approximately $40 \mathrm{~m}$ of overconsolidated clay till with a varying degree of weathering, fissuring and stone inclusions, underlain by chalk (Fig. 4(a)). There are also two approximately $1 \mathrm{~m}$ thick sand layers at depths of around $12 \mathrm{~m}$ and $18 \mathrm{~m}$, reported by Powell \& Butcher (2003) as variable, in terms of depth, over their site. The groundwater table was found $1 \mathrm{~m}$ below the ground surface, while both historic (Robson, 1988) and new piezometric measurements indicate that the deeper pore water pressures are under-drained, with values in the unweathered till being considerably lower than hydrostatic, as shown in Fig. 4(a). This feature is possible if there exists a deep aquifer with a phreatic surface lower than the groundwater table and if the permeability, $k$, reduces significantly with depth (Vaughan, 1994), which was confirmed by Powell \& Butcher (2003) who reported, from field tests, $k \approx 0.05 \mathrm{~m} /$ year in the weathered till and $k=0.0005$ to $0.007 \mathrm{~m} /$ year in the unweathered till. The solid line represents the interpreted pore water pressure profile, which is consistent with the soil permeability in the top $12 \mathrm{~m}$ (Zdravkovic et al., 2019) and is assumed hydrostatic at depth.

Local variations are expected in glacial sediments and new site investigations performed for PISA included two Geobor-S rotary sample boreholes to about $15 \mathrm{~m}$ depth and multiple seismic and piezocone penetration (SCPT and $\mathrm{CPTu}$ ) tests. The locations of the boreholes and in situ tests are marked in the 'site detail' in Fig. 3(a). The Geobor-S triple-barrel wireline rotary coring system was deployed to obtain high-quality samples. It incorporated a plastic liner with a nominal $100 \mathrm{~mm}$ dia. and a length of $1.5 \mathrm{~m}$, a second barrel which accommodated the plastic liner and an outer barrel ending with an annular drilling bit and drilling fluid flushing system. A core-catcher placed just behind the cutting shoe holds the sample inside the liner. These cores were trimmed to produce 100 and $38 \mathrm{~mm}$ dia. samples for triaxial experiments and $65 \mathrm{~mm}$ dia. samples for oedometer testing, by holding the core in a steel fame and trimming with a combination of a knife, for initial crude shaping, and a wire for the final fine shaping of the samples. Continuous mist spraying was applied in a dedicated sample preparation room to minimise drying of the samples.
Index testing on the new samples confirmed the historic profiles. A summary of average index properties is given in Table 1, with further details available in Powell \& Butcher (2003). A uniform plasticity index, PI, of about $18 \%$ on average is reported, beneath a more plastic shallow surface layer (about $1 \mathrm{~m}$ thick) with $\mathrm{PI}=37 \%$. The clay content is uniform at about $32 \%$ on average, while the bulk unit weight of the soil is $21 \cdot 19 \mathrm{kN} / \mathrm{m}^{3}$. The particle size analysis of samples in the top $10 \mathrm{~m}$ of the deposit, using wet sieving and sedimentation by pipette methods, showed $90 \%$ of particles to be smaller than $1 \mathrm{~mm}$ and $10 \%$ between $1 \mathrm{~mm}$ and $10 \mathrm{~mm}$.

New cone tip resistance traces, $q_{\mathrm{t}}$, from CPT tests, taken at locations of each pile ( $\mathrm{M}$ and $\mathrm{L}$ in the 'site detail' in Fig. 3(a)) and shown in Fig. 4(b), were reasonably consistent and confirmed the existence of a sand layer at about $12 \mathrm{~m}$ depth across the PISA site. To avoid any interaction with this layer, a maximum penetration depth of $10.5 \mathrm{~m}$ was prescribed for the test piles (see Burd et al., 2019).

Establishing a $K_{0}$ profile is critical to both stress path laboratory testing and advanced numerical modelling. Powell \& Butcher (2003) estimated $K_{0}$ by considering: $(a)$ sample suctions, which can be misleading due to the effects of tube sampling, and $(b)$ the profile with depth of apparent overconsolidation ratio (OCR), linking this to $K_{0}$ through empirical expressions developed for monotonically overconsolidated pluviated sediments. However, Jardine (1985) argued that glacial lodgement till deposition does not impose the high $K_{0}$ ratios suggested by such an approach, especially at shallow depth. Recent research with aged, stiff, high-OCR marine clays that have experienced weathering and glacial cycles, has shown that they cannot sustain $K_{0}$ values greater than 1.5 to 1.75 at depths of $10 \mathrm{~m}$ or less (Brosse et al., 2017). Considering all the available information, it was decided to assume an upper limit of 1.5 to the $K_{0}$ trend suggested by Powell \& Butcher (2003), as shown in Fig. 5.

\section{Behaviour in one-dimensional (1D) compression}

A new set of constant rate of strain (CRS) oedometer experiments was conducted by Geolabs. Samples of Cowden till, $65 \mathrm{~mm}$ in diameter and $19 \mathrm{~mm}$ high, from five depths

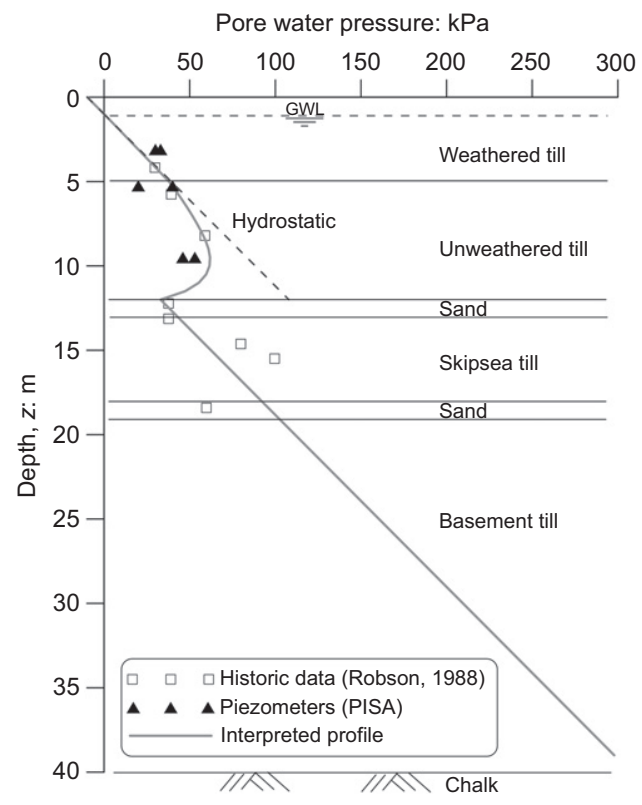

(a)

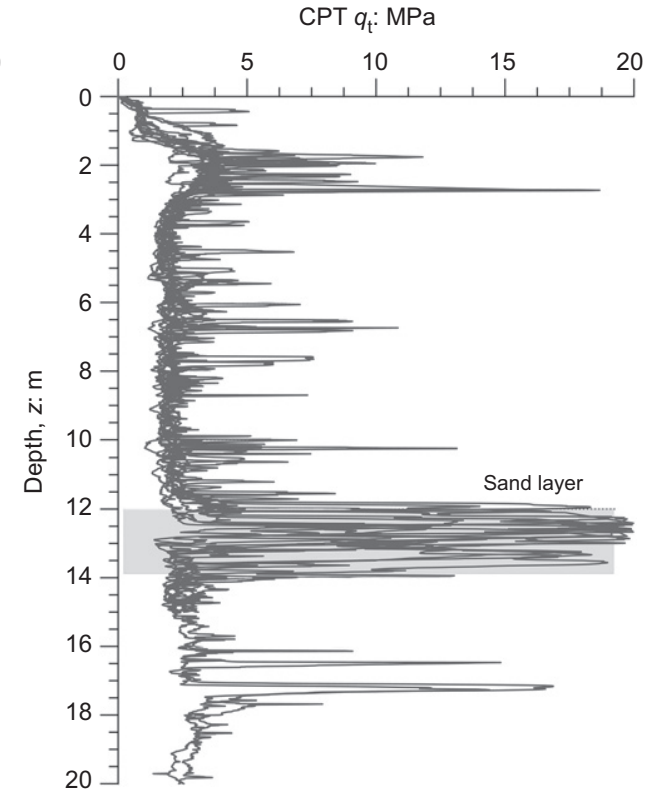

(b)

Fig. 4. Cowden ground profile: (a) pore water pressure; (b) CPT cone resistance, $q_{t}$ 
Table 1. Index properties for Cowden till - average for the profile below top 1.0 m

\begin{tabular}{l|l|l|l|l|l|l|l|l}
\hline$\rho: \mathrm{Mg} / \mathrm{m}^{3}$ & $w / c: \%$ & PL: $\%$ & LL: $\%$ & PI: $\%$ & $G_{\mathrm{s}}$ & Clay content: $\%$ & Organic content: $\%$ & Carbonate content: $\%$ \\
\hline $2 \cdot 16$ & 16.5 & 16 & 34 & 18 & $2 \cdot 71$ & 32 & 1.4 & 6.6 to 12 \\
\hline
\end{tabular}

$\rho$, bulk density; $w / c$, water content; PL, plastic limit; LL, liquid limit; PI, plasticity index; $G_{\mathrm{s}}$, specific gravity.

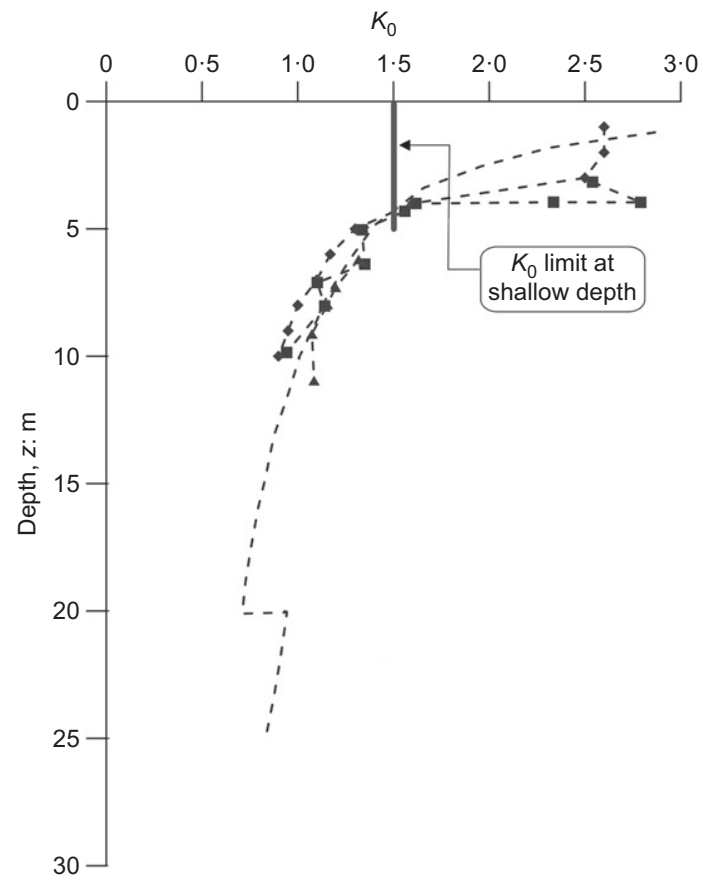

Fig. 5. $K_{0}$ profile at Cowden: trends from Powell \& Butcher (2003), with upper limit of 1.5 applied

down to $10 \cdot 15 \mathrm{~m}$, were tested both in their intact and reconstituted states. Fig. 6 plots the corresponding void ratio, $e$, against the vertical effective stress, $\sigma_{\mathrm{v}}^{\prime}$, for each depth, showing that the shallow material $(0.74 \mathrm{~m})$ is much more plastic and compressible (in agreement with its higher PI) than deeper samples. The latter samples indicate relatively little difference between the weathered and unweathered till.

In comparison with the reconstituted curves, it is also clear from Fig. 6 that the natural till showed only progressive 1D compression, with no clear yield points, indicating a stable

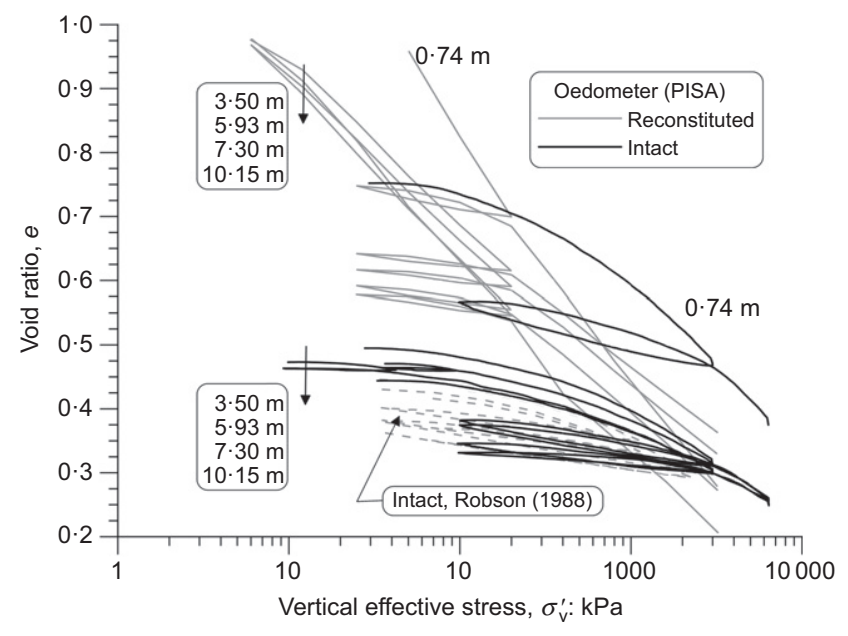

Fig. 6. One-dimensional compression of Cowden till samples natural structure even when compressed to $6 \mathrm{MPa}$ vertical effective stress. Added to the figure are the historic oedometer data from intact samples, summarised in Robson (1988), which agree with the new set of compression and swelling curves from the deeper material. The average intact compressibility coefficient, $C_{\mathrm{C}}$, for the deeper samples is $0 \cdot 16$, compared to $0 \cdot 28$ for the shallowest, while the average swelling index, $C_{\mathrm{S}}$, is $0 \cdot 047$. In critical state soil mechanics terms, the intact compressibility, $\lambda$, that relates specific volume, $v(=1+e)$, to mean effective stress, $p^{\prime}$, varies from 0.062 in the deeper deposit to about 0.12 in the shallow surface layer, while the reconstituted gradient ranges from $0 \cdot 1$ to $0 \cdot 17$, respectively. The swelling coefficient, $\kappa$, ranges between $0 \cdot 012$ and $0 \cdot 021$.

\section{Behaviour in triaxial testing}

Equipment and testing procedure. The characterisation presented in this paper was developed from the triaxial testing conducted on Cowden till (Ushev et al., 2015), with the test programme summarised in Table 2. Sample descriptions confirmed the stony nature of the deposit, as well as some sub-vertical fissuring, particularly in the shallow layers. The testing involved both $38 \mathrm{~mm}$ and $100 \mathrm{~mm}$ dia. samples, with a height to diameter ratio of 2 , in an automated stress-path apparatus designed at Imperial College. While the

Table 2. Summary of new Cowden till triaxial tests and their initial conditions

\begin{tabular}{l|c|c|c}
\hline Test code & $\begin{array}{c}\text { Pre-shear } p_{0}^{\prime}: \\
\mathrm{kPa}\end{array}$ & $\begin{array}{c}\text { Pre-shear } \sigma_{\mathrm{v}}^{\prime} \text { : } \\
\mathrm{kPa}\end{array}$ & $\begin{array}{c}\text { Pre-shear } \\
K_{0}\end{array}$ \\
\hline CR38KUC0.5 & $19 \cdot 3$ & $14 \cdot 5$ & $1 \cdot 5$ \\
CR38KUC1.0 & $27 \cdot 7$ & $20 \cdot 8$ & $1 \cdot 5$ \\
CR38KUC1.5 & $35 \cdot 5$ & $26 \cdot 6$ & $1 \cdot 5$ \\
CR100KUC2.0 & $46 \cdot 4$ & $34 \cdot 8$ & $1 \cdot 5$ \\
CR100KUC2.5 & $54 \cdot 8$ & $41 \cdot 1$ & $1 \cdot 5$ \\
CR38KUC3.0T & $62 \cdot 4$ & $46 \cdot 8$ & $1 \cdot 5$ \\
CR38KUC3.7 & $70 \cdot 2$ & $52 \cdot 6$ & $1 \cdot 5$ \\
CR100KUC5.0 & $92 \cdot 7$ & $69 \cdot 5$ & $1 \cdot 5$ \\
CR38KUC5.0 & $76 \cdot 2$ & 57 & $1 \cdot 5$ \\
CR38KUC5.4 & $96 \cdot 6$ & $72 \cdot 5$ & $1 \cdot 5$ \\
CR38IUC8.0 & $113 \cdot 5$ & $113 \cdot 5$ & $1 \cdot 0$ \\
CR38IUC8.0 & $113 \cdot 8$ & $113 \cdot 8$ & $1 \cdot 0$ \\
CR100IUC8.2 & 121 & 121 & $1 \cdot 0$ \\
CR38IUC10.0 & $156 \cdot 2$ & $156 \cdot 2$ & $1 \cdot 0$ \\
CR38IUC10.0 & $153 \cdot 1$ & $153 \cdot 1$ & $1 \cdot 0$ \\
CR38IUC11.5 & 198 & 198 & $1 \cdot 0$ \\
CR38KUE0.5 & $19 \cdot 7$ & $14 \cdot 7$ & $1 \cdot 5$ \\
CR38KUE1.0 & $27 \cdot 5$ & $20 \cdot 6$ & $1 \cdot 5$ \\
CR38KUE3.4 & $65 \cdot 9$ & $49 \cdot 4$ & $1 \cdot 5$ \\
CR100KUE4.5 & $80 \cdot 2$ & $60 \cdot 2$ & $1 \cdot 5$ \\
CR38KUE5.4 & $97 \cdot 5$ & $73 \cdot 1$ & $1 \cdot 5$ \\
CR38IUE7.5 & $113 \cdot 5$ & $113 \cdot 5$ & $1 \cdot 0$ \\
CR38IUE10.0 & $153 \cdot 6$ & $153 \cdot 6$ & $1 \cdot 0$ \\
\hline Tes & &
\end{tabular}

Test code: C, Cowden site; R, rotary core samples; 38 or 100 , sample diameter in millimetres; $\mathrm{K}$ or $\mathrm{I}, K_{0}$ or isotropic consolidation; $\mathrm{U}$, undrained shearing; $\mathrm{C}$ or $\mathrm{E}$, compression or extension shearing mode; $X . Y$ - sample depth below ground surface, ranging from 0.5 to $11.5 \mathrm{~m}$. 
larger diameter cells offered better instrumentation resolution and more representative element volumes, the $38 \mathrm{~mm}$ samples were quicker to consolidate and allowed a larger number of tests to be performed within the limited time available. Sufficient parallel testing was undertaken on both sample sizes to assess their effect on the test results. As discussed later, the main test outcomes were not unduly sensitive to sample size. Despite the till's stony nature, its finer matrix dominates its mechanical properties, which appear to be represented adequately by both sample sizes.

The experimental capabilities are broadly as described by Gasparre et al. (2007), Hosseini Kamal et al. (2014), Al Haj (2014), Ackerley et al. (2016) and Brosse et al. (2017). The triaxial samples were instrumented to measure local axial, $\varepsilon_{\mathrm{a}}$, and radial, $\varepsilon_{\mathrm{r}}$, strains using a system of linear variable differential transformers (LVDTs). The $100 \mathrm{~mm}$ dia. samples were also equipped with mid-height pore water pressure probes and both vertical and lateral sets of bender elements (BEs) to measure shear wave velocities. The latter included T-shaped BEs that were mounted at diametrically opposite positions at the mid-height of the sample. These allowed the velocities linked to the potentially different $G_{\mathrm{hv}}$ and $G_{\mathrm{hh}}$ stiffness components to be measured independently at various test stages, as described by Kuwano \& Jardine (1998) and Gasparre et al. (2007).

The experimental procedure involved re-consolidation of all samples to the estimated in situ effective stresses. A rest period was then allowed until creep strain rates diminished to less than 0.005\%/day. Monotonic undrained (U) shearing followed in either compression (TXC) or extension (TXE). Control based on the mid-height pore water pressure data ensured that all swelling or consolidation processes were completed before shearing. A shearing axial strain rate of 5\% per day was chosen to ensure uniform pore pressures in the samples during undrained loading, which was also checked with the mid-height probes.

In general, all stress-strain curves for both weathered and unweathered samples sheared in compression showed ductile behaviour after being compressed in excess of $20 \%$ axial strain. Most specimens reached stable final critical stress states, undergoing barrelling failures without any clear bifurcation. Samples sheared in extension experienced premature necking-type failure from about $6 \%$ axial strain. Similar behaviour was reported by Hight (1982), Gens (1982) and Gens \& Hight (1979) from tests on the lower plasticity $(\mathrm{PI}=12 \%)$ Lower Cromer till from the UK's Norfolk coast, and by Jardine (1985) in tests on natural, overconsolidated, low-plasticity till $(\mathrm{PI}=18 \%$ ) from the Magnus offshore field in the northern North Sea.

Interpretation of stiffness. Recent research on high-OCR, aged, marine stiff clays indicates that their elastic stiffness, which operates over a very small strain range, may be markedly anisotropic, with horizontal (drained or undrained) Young's moduli far exceeding the vertical values measured in triaxial compression tests. Similarly, $G_{\mathrm{hh}}$ stiffnesses from BE testing far exceeded the $G_{\mathrm{vh}}$ values measured in the same experiments, with field seismic profiling indicating compatible evidence of in situ elastic stiffness anisotropy (e.g. Gasparre et al., 2007; Brosse, 2012; Brosse et al., 2017).

The laboratory tests and field seismic wave velocity measurements undertaken for Cowden provide a similarly broad range of information on the Cowden till's elastic shear modulus in Fig. 7. The interpreted maximum isotropic shear modulus profile, $G_{0}$, from local transducer measurements in undrained triaxial tests at axial strain levels of about $10^{-4} \%$,

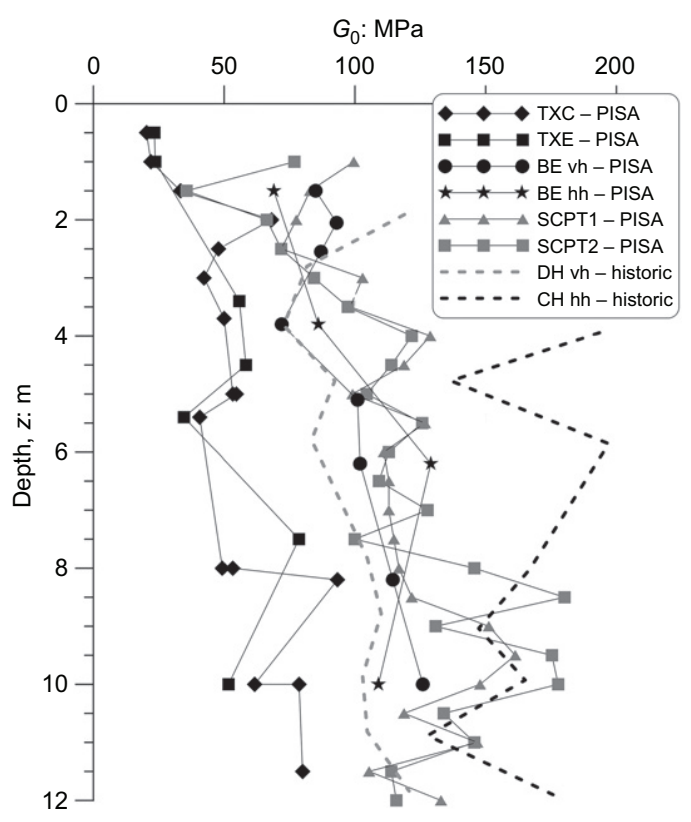

Fig. 7. $G_{0}$ profiles established by various means for Cowden till

shows reasonable agreement between triaxial compression (TXC) and extension data (TXE), as expected within the elastic range. Added to this are the interpreted $G_{\mathrm{vh}}$ and $G_{\mathrm{hh}}$ stiffness profiles from the $\mathrm{BE}$ data, which indicate that $G_{\mathrm{vh}}<G_{\mathrm{hh}}$, but not as markedly as for marine stiff clays. Although not plotted, the BE tests indicated that $G_{\mathrm{hv}}=G_{\mathrm{vh}}$. Stiffness profiles are also shown from the interpretation of two SCPT tests, which agree closely with BE tests and therefore indicate little sample disturbance with Geobore-S sampling. The interpreted $G_{\mathrm{vh}}$ stiffness from historic downhole (DH) geophysics is broadly in agreement with the new data from dynamic soil testing, while the $G_{\mathrm{hh}}$ stiffness, from historic crosshole $(\mathrm{CH})$ geophysics, indicates greater divergence between the two profiles, which could be attributed to the reported local site variability in the study of Powell \& Butcher (2003).

The stiffness of geomaterials is widely recognised to be pressure dependent. When interpreted as isotropic, the shear stiffness is considered proportional to a power of the mean effective stress (i.e. $\left.G \propto\left(p^{\prime}\right)^{n}\right)$, with the exponent $n$ ranging from about 0.5 to $1 \cdot 0$. While some researchers have reported $n$ increasing with the deformation level towards unity (e.g. Jardine, 1995; Viggiani \& Atkinson, 1995; Jovicic \& Coop, 1997), recent stiffness measurements in geologically aged Gault, Kimmeridge and Oxford stiff marine clays (Brosse et al., 2017) have suggested the opposite. Moreover, the classical critical state framework assumes that swelling lines of clay materials have constant slopes in the $v-\ln p^{\prime}$ plane and, therefore, that the bulk stiffness is directly proportional to $p^{\prime}$. Consequently, the test results on Cowden till are interpreted assuming a similar linear dependency of the shear stiffness on the mean effective stress (i.e. $n=1 \cdot 0$ ). Fig. 8 summarises the degradation of the normalised secant shear stiffness, $G_{\text {sec }} / p^{\prime}$, with increasing deviatoric strain $\left(E_{\mathrm{d}}=(2 / 3)\left(\varepsilon_{\mathrm{a}}-\varepsilon_{\mathrm{r}}\right)\right)$, interpreted from the locally instrumented triaxial tests. The data show a large range of measured values for any given strain, with samples extracted from the top $2 \mathrm{~m}$ of weathered till showing the highest $G_{\mathrm{sec}} / p^{\prime}$ ratio. However, all tests have a consistent pattern of stiffness degradation with strain. The shaded range of historic data is representative of insufficient instrumentation accuracy at very small strains, but indicates a similar range of variability at medium to large strains. 


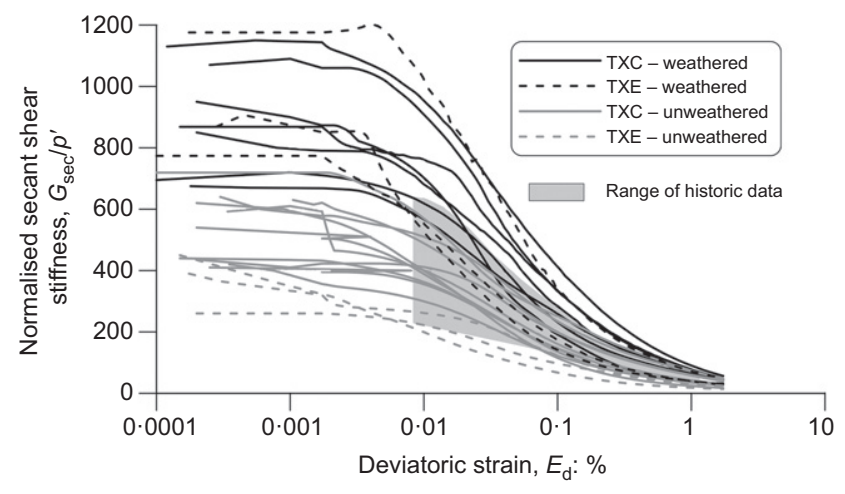

Fig. 8. Normalised secant shear stiffness from undrained triaxial tests on Cowden till samples

Interpretation of strength. The effective stress shear strength characteristics of Cowden till are discussed first, referring to the undrained tests on high-quality samples (Table 2), which were conducted to match the effectively undrained conditions under which the PISA piles reached their failure conditions. Fig. 9 shows stress ratio $\left(q / p^{\prime}\right)$ plotted against axial strain curves for all tests, separating weathered (less than $5 \mathrm{~m}$ depth) from the deeper unweathered samples. Slight variations can be seen between the two sample groups in terms of their ultimate strengths, both in compression and extension. Stress conditions at critical states, derived from individual tests at axial strains of around $30 \%$ in compression and $15 \%$ in extension, are plotted in the $q-p^{\prime}$ space in Fig. 10, indicating close agreement. The implication is that weathering, as well as sample size, has little effect on the interpreted critical state strengths. The historic data, obtained by testing

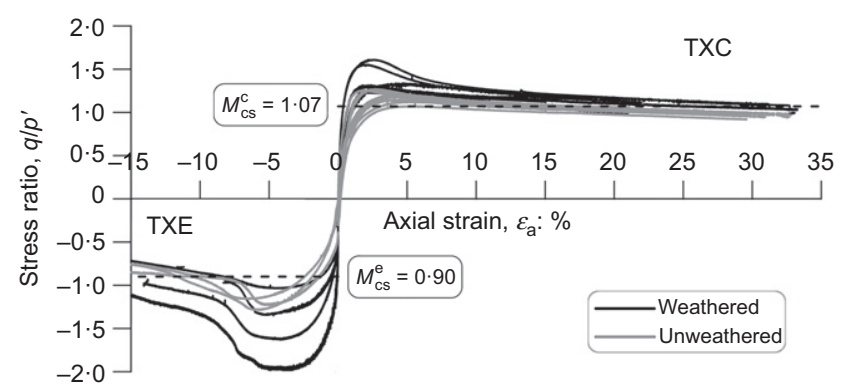

Fig. 9. Normalised stress-strain curves from the shearing stages of Cowden till samples

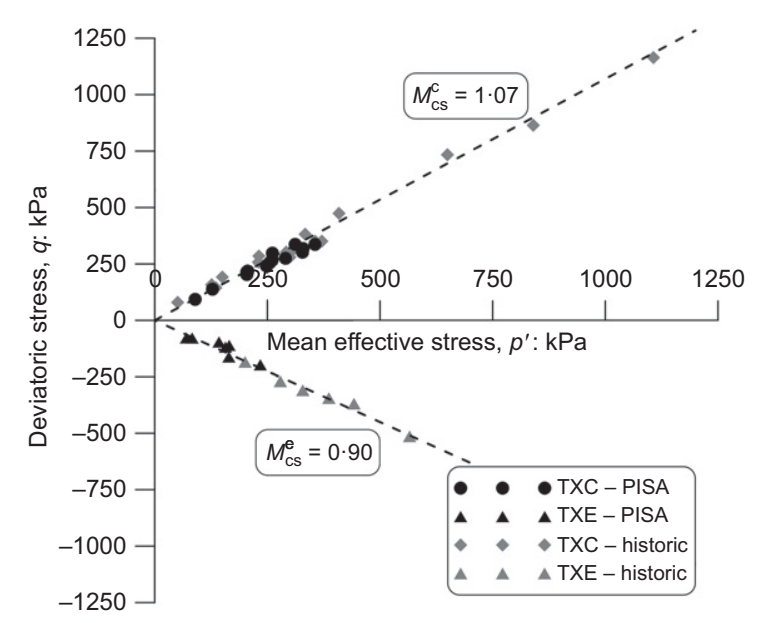

Fig. 10. Interpretation of Cowden till effective stress shear strengths
Cowden till specimens from pushed-in samplers, are interpreted in the same manner and added to Fig. 10, contributing additional information on strength for the deeper part of the deposit. Both new and historic sets of data plot closely together, resulting in average ultimate stress ratios, $M_{\mathrm{cs}}^{\mathrm{c}, \mathrm{e}}=q / p^{\prime}$, of $1.07 \quad\left(=6 \sin \phi_{\mathrm{TXC}}^{\prime} /\left(3-\sin \phi_{\mathrm{TXC}}^{\prime}\right)\right)$ and 0.90 $\left(=6 \sin \phi_{\mathrm{TXE}}^{\prime} /\left(3+\sin \phi_{\mathrm{TXE}}^{\prime}\right)\right)$ in triaxial compression and triaxial extension, respectively. These values correspond to angles of shearing resistance at critical state of $\phi_{\mathrm{TXC}}^{\prime}=27^{\circ}$ and $\phi_{\mathrm{TXE}}^{\prime}=32^{\circ}$, suggesting the existence of a considerable degree of Lode's angle dependency and/or strength anisotropy in this material.

The undrained shear strength, $S_{\mathrm{u}}$, is assessed next, with Fig. 11(a) summarising both historic (Powell \& Butcher, 2003) and new data from triaxial compression tests (TXC). In addition, new hand shear vane (HSV) tests were conducted in the field that, together with CPT tests, supplemented the interpretation of the complex profile shape developed at this glacial clay site. Most of the historic sampling involved pushed-in thin-walled steel tubes, $700 \mathrm{~mm}$ long and $98 \mathrm{~mm}$ in diameter. Samples were also obtained by hammering in U4 sampling tubes (about $100 \mathrm{~mm}$ dia.), as well as by vibro and rotary coring. The historic data are presented as grey symbols, showing sizable scatter and no definition of strength in the top $2 \mathrm{~m}$. Some of the deviations in the historic characterisation were explained by Powell \& Butcher (2003) as genuine site variability (e.g. data at location BHTE in Fig. 11(a)). Additionally, they also refer to the samples as being of 'reasonable' quality and affected by some sample disturbance. By comparison, the new triaxial data from Geobore-S rotary coring are consistent and of high quality and the $S_{\mathrm{u}}$ values from $38 \mathrm{~mm}$ and $100 \mathrm{~mm}$ dia. samples from similar depths show close agreement, confirming that the sample size was not a dominant factor in the laboratory testing. Further inspection of Fig. 11(a) also shows that the new tests enabled the $S_{\mathrm{u}}$ profile above $2 \mathrm{~m}$ to be established, while at depth the new data plot towards the upper range of the historic data points. Fig. 11(b) adds to the new laboratory data the average $S_{\mathrm{u}}$ profile interpreted from the new CPT cone resistances, $q_{\mathrm{t}}$ (applying a cone factor $N_{\mathrm{kt}}=16$ after Powell \& Quarterman (1988)). The erratic nature of the profile reflects the presence of stone inclusions as spikes with higher resistance. If these are ignored, then a generally good agreement is seen between the laboratory and field interpretations of undrained strength. Consequently, the new testing provided a significantly more consistent and convincing basis for interpreting the $S_{\mathrm{u}, \mathrm{TXC}}$ profile, as indicated by the dashed line in Figs 11(a) and 11(b).

\section{DUNKIRK SITE}

\section{Ground conditions}

The ground profile at Dunkirk was established during previous piling research projects on the site, in particular the French CLAROM project (Brucy et al., 1991) and the studies reported by Chow (1997), supported by the laboratory study of Kuwano (1999). This is a coastal site in northern France and the material is a normally consolidated marine sand, from $3 \mathrm{~m}$ down to $30 \mathrm{~m}$ depth, below which Ypresian Eocene marine clay is found. The upper $3 \mathrm{~m}$ consists of a hydraulically laid sand fill of the same origin, placed in the 1970 s, with no compaction or surcharging, to raise the ground level. Chow (1997) reported the groundwater table at $4 \mathrm{~m}$ depth, with hydrostatic conditions beneath.

Rotary cores were taken for the CLAROM programme and were shared with Imperial College in the 1990s. Particle size analyses showed the sand composition varying marginally with depth and classifying on average as uniform and fine to medium. The average index properties summarised in 


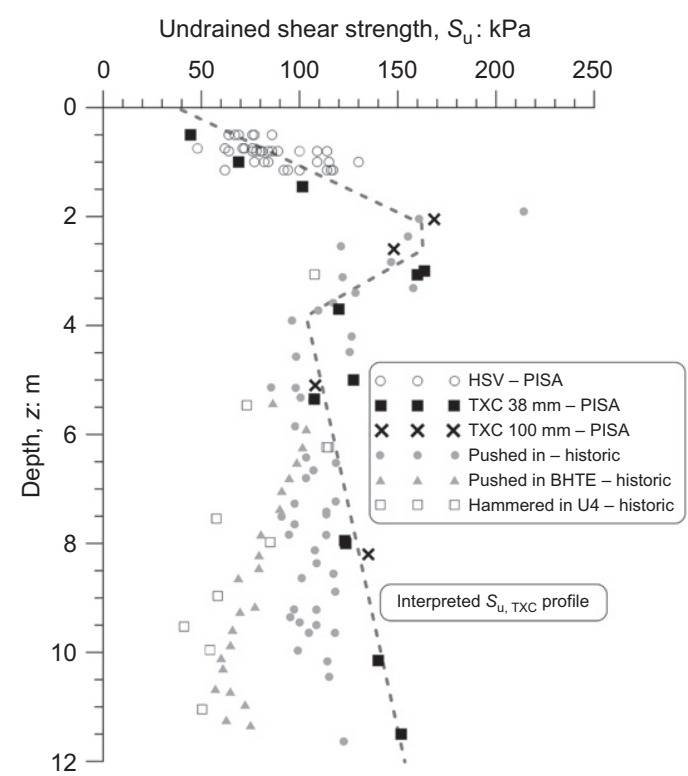

(a)

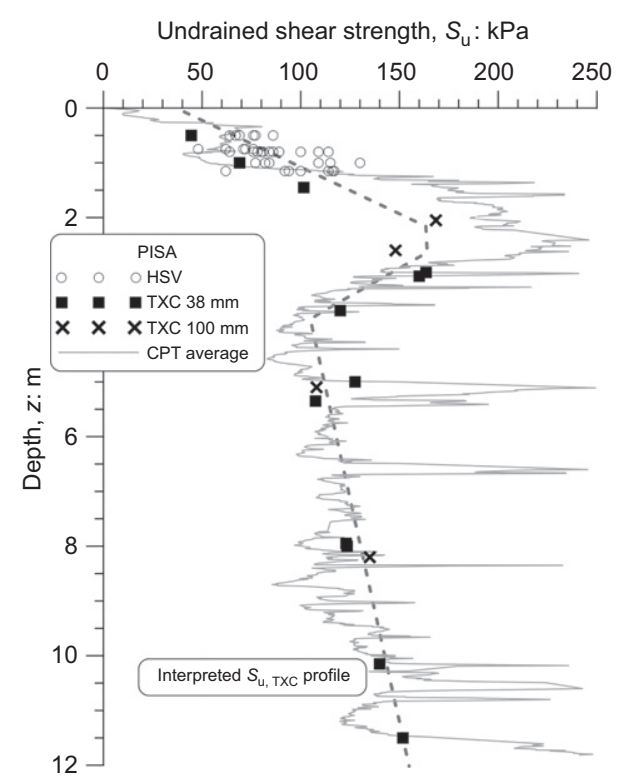

(b)

Fig. 11. Undrained strength profile at Cowden: (a) comparison of new and historic data; (b) comparison with CPT interpretation

Table 3 were confirmed in the study of Kuwano (1999). The sand contains shell fragments but has an $84 \%$ quartz content (Chow, 1997). Based on CPT results and the Lunne \& Christofferson (1983) correlation between cone resistance, $q_{\mathrm{t}}$, and relative density, $D_{\mathrm{R}}$, Chow (1997) concluded that the hydraulic fill layer may be assumed as $100 \%$ dense, with the natural deposit underneath being at $D_{\mathrm{R}}=75 \%$. The bulk unit weight above and below the water table was estimated at $17 \cdot 1 \mathrm{kN} / \mathrm{m}^{3}$ and $19.9 \mathrm{kN} / \mathrm{m}^{3}$, respectively. Chow (1997) further assumed the earth pressure coefficient, $K_{0}$, to be $0 \cdot 4$, which was adopted for the PISA study.

New CPT tests were carried out across the site at each pile location, together with some SCPT testing, with their positions shown in the layout in Fig. 3(b). The cone resistance, $q_{\mathrm{t}}$, traces in Fig. 12(a) show a reasonably uniform profile across the site. The groundwater was found to be at $5.4 \mathrm{~m}$ depth, Fig. 12(b), deeper than previously observed. The PISA test area was located around $100 \mathrm{~m}$ from the previous site; consequently, the groundwater table and CPT profile variations might be attributable to local site variability and/or the effects of ageing under the hydraulic fill over the past 20 years. Two different correlations were applied to estimate the relative density, $D_{\mathrm{R}}$, profiles from the $q_{\mathrm{t}}$ traces, with that of Baldi et al. (1986) indicating a relative density in excess of $100 \%$ throughout the deposit, whereas the Kulhawy \& Mayne (1990) expression led to relative densities closer to those estimated by Chow (1997), with $D_{\mathrm{R}} \approx 75 \%$ being an average for the reducing cone resistance between 3 and $9 \mathrm{~m}$ depth. Consequently, and also due to the differences in $D_{\mathrm{R}}$ magnitudes from different correlations, $D_{\mathrm{R}}=75 \%$ in the natural sand and $D_{\mathrm{R}}=100 \%$ in the fill were adopted for the initial density profile, as a compromise between the new and the historic data.

Table 3. Index properties for Dunkirk sand (after Kuwano, 1999)

\begin{tabular}{l|c|c|c|c}
\hline$G_{\mathrm{s}}$ & $e_{\max }$ & $e_{\min }$ & $C_{\mathrm{U}}$ & $D_{50}: \mathrm{mm}$ \\
\hline 2.65 & 0.91 & 0.54 & 1.72 & 0.28 \\
\hline
\end{tabular}

$G_{\mathrm{s}}$ - specific gravity; $e_{\max }-$ maximum void ratio; $e_{\min }-$ minimum void ratio; $C_{\mathrm{U}}$ - coefficient of uniformity; $D_{50}$ - particle diameter at which $50 \%$ of the sample's particles are smaller than this diameter.
Kuwano (1999) reported triaxial testing whose principal emphasis was the assessment of the sand's elastic stiffness, rather than its ultimate strength. For the latter, use was made of research by Aghakouchak (2015) conducted at Imperial College on bulk samples taken at shallow depth, which were shown to be broadly representative of the average composition encountered over the moderately variable Dunkirk profile. At the start of the PISA project, three drained triaxial compression tests were available, performed on $K_{0}$-consolidated samples with $e_{0} \approx 0.64$ (corresponding to the estimated natural $D_{\mathrm{R}}$ of about $75 \%$ ) at three different stress levels $\left(p^{\prime}=150,300\right.$ and $\left.500 \mathrm{kPa}\right)$. A further three tests were carried out in extension on samples prepared to the same initial conditions. No high-quality borehole sampling was completed for PISA at Dunkirk.

\section{Behaviour in triaxial testing}

Equipment and testing procedure. Liu et al. (2017) undertook a suite of new triaxial tests on $38 \mathrm{~mm}$ dia. samples, summarised in Table 4, to supplement the data from Aghakouchak (2015) by examining a wider range of void ratios, stress levels and stress histories on samples isotropically consolidated to $p^{\prime}$ of $50,100,150$ and $400 \mathrm{kPa}$. Equipment similar to that used for the Cowden testing was employed, although a BE set up was not deployed. Sieving and index tests confirmed that the different test batches of Dunkirk sand had comparable characteristics.

The majority of tests were conducted at an initial void ratio $e_{0} \approx 0.64 \quad\left(D_{\mathrm{R}} \approx 75 \%\right)$, with values of $e_{\min }=0.54$ and $e_{\max }=0.91$, corresponding to samples from around $5 \mathrm{~m}$ depth (Kuwano, 1999), which is the mid-depth of the largest PISA test piles. A limited number of tests examined looser and denser samples with $D_{\mathrm{R}}$ of about $45 \%\left(e_{0} \approx 0 \cdot 74\right)$ and $85 \%\left(e_{0} \approx 0 \cdot 59\right)$, respectively. Table 4 summarises the actual $e_{0}$ values at the start of shearing of each test.

The samples were formed by water pluviation, which is the most appropriate approach for reproducing the structure of water-borne natural sediments. After saturation, all samples were isotropically consolidated/swelled back to the desired initial value of $p^{\prime}$. A rest period was allowed until creep strains diminished to very low residual strain rates (less than $0 \cdot 002 \% /$ day). The majority were then sheared monotonically 

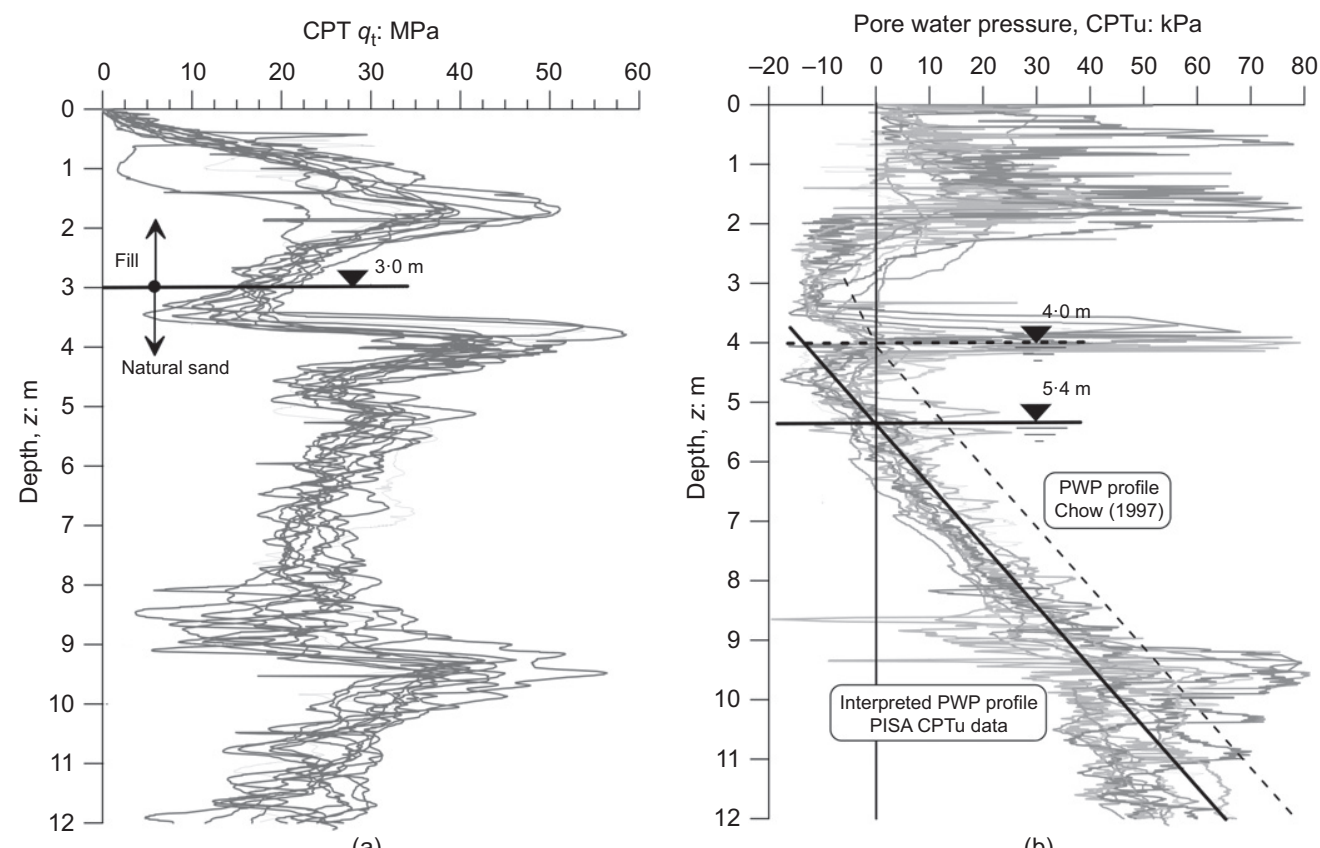

(a)

(b)

Fig. 12. Dunkirk ground profile: (a) CPT cone resistance, $q_{t}$; (b) pore water pressure

Table 4. Summary of new Dunkirk sand triaxial tests and their initial conditions

\begin{tabular}{|c|c|c|c|c|}
\hline Test & Initial void ratio, $e_{0}$ & Pre-shear $p_{0}^{\prime}: \mathrm{kPa}$ & Pre-shear OCR & Pre-shear $K_{0}$ \\
\hline $1(\mathrm{C})$ & $0 \cdot 640$ & 50 & $1 \cdot 0$ & $1 \cdot 0$ \\
\hline $2(\mathrm{C}, \mathrm{E})$ & $0.639 ; 0.636$ & 100 & $1 \cdot 0$ & $1 \cdot 0$ \\
\hline $3(\mathrm{C})$ & 0.637 & 150 & $1 \cdot 0$ & $1 \cdot 0$ \\
\hline $4(\mathrm{C})$ & 0.633 & 400 & $1 \cdot 0$ & $1 \cdot 0$ \\
\hline $5(\mathrm{C})$ & $0 \cdot 584$ & 100 & $1 \cdot 0$ & $1 \cdot 0$ \\
\hline $6(\mathrm{C})$ & $0 \cdot 730$ & 100 & $1 \cdot 0$ & $1 \cdot 0$ \\
\hline 7 (C) & $0 \cdot 723$ & 200 & $1 \cdot 0$ & $1 \cdot 0$ \\
\hline $7(\mathrm{C}, \mathrm{E})$ & $0 \cdot 724 ; 0 \cdot 723$ & 400 & $1 \cdot 0$ & $1 \cdot 0$ \\
\hline $8(\mathrm{C})$ & 0.638 & 50 & $4 \cdot 0$ & $1 \cdot 0$ \\
\hline 9 (C) & $0 \cdot 630$ & 100 & $4 \cdot 0$ & $1 \cdot 0$ \\
\hline $10(\mathrm{C})$ & 0.632 & 150 & $4 \cdot 0$ & $1 \cdot 0$ \\
\hline $11(\mathrm{C})$ & 0.639 & 50 & $12 \cdot 0$ & $1 \cdot 0$ \\
\hline $12(\mathrm{C})$ & $0 \cdot 583$ & 100 & $4 \cdot 0$ & $1 \cdot 0$ \\
\hline 13 (C) & 0.726 & 100 & $4 \cdot 0$ & $1 \cdot 0$ \\
\hline
\end{tabular}

under drained compression (C), with just two samples subjected to drained extension (E). An axial strain rate of $5 \%$ per day was chosen to ensure full drainage during shearing and to allow high-quality small-strain measurements to be made over the early stages of shearing.

Interpretation of stiffness. The new laboratory experiments allowed the interpretation of small-strain stiffness only from local instrumentation on triaxial samples. Consequently, the equivalent isotropic elastic shear modulus, $G_{0}$, was interpreted from these tests, examining its dependency on OCR, mean effective stress $\left(p^{\prime}\right)$ and void ratio $(e)$, using the classical expression of Hardin \& Black (1968)

$$
G_{0}=A p_{\text {ref }}^{\prime} f(e) \operatorname{OCR}^{m}\left(p^{\prime} / p_{\text {ref }}^{\prime}\right)^{n}
$$

with $f(e)$ being a function introducing the effect of void ratio on $G_{0}$, while $p_{\text {ref }}^{\prime}$ is a reference pressure assumed equal to atmospheric pressure $(101.3 \mathrm{kPa})$. In the present case, the adopted form for $f(e)$ was that proposed by Hardin \& Black (1966), $f(e)=(2 \cdot 97-e)^{2} /(1+e)$.
The estimated maximum shear modulus values, $G_{0}$, from samples with the same initial void ratio $e_{0}=0 \cdot 64$, are plotted in Fig. 13 against $p^{\prime}$, demonstrating that OCR has practically no influence on the stiffness within the elastic range. This has been observed in other studies on sands and is discussed by Zhou \& Chen (2005), who concluded that the effect of previous stress history on $G_{0}$ is not significant when sands are subjected to low-strain-amplitude cyclic shearing. This allows the parameter $m$ in equation (1) to be set to 0 , thus removing the effect of OCR. Re-plotting all data from both the new and Aghakouchak (2015) triaxial tests within the modified set of axes, $G_{0} /\left[p_{\text {ref }}^{\prime} f(e)\right]$ and $p^{\prime} / p_{\text {ref }}^{\prime}$, in Fig. 14 enables the fitting of parameters $A$ and $n$ in equation (1). Both data sets can be fitted well with $n=0 \cdot 5$, which agrees with the values observed for other sands, but follow different curves due to different consolidation conditions pre-shearing (Kuwano, 1999; Kuwano \& Jardine, 2002), the former being isotropically consolidated and the latter $K_{0}$ consolidated.

An alternative proposal for $G_{0}$ of Hardin (1978) is examined next, as it is used in several constitutive models for sands (e.g. Papadimitriou \& Bouckovalas, 2002; 


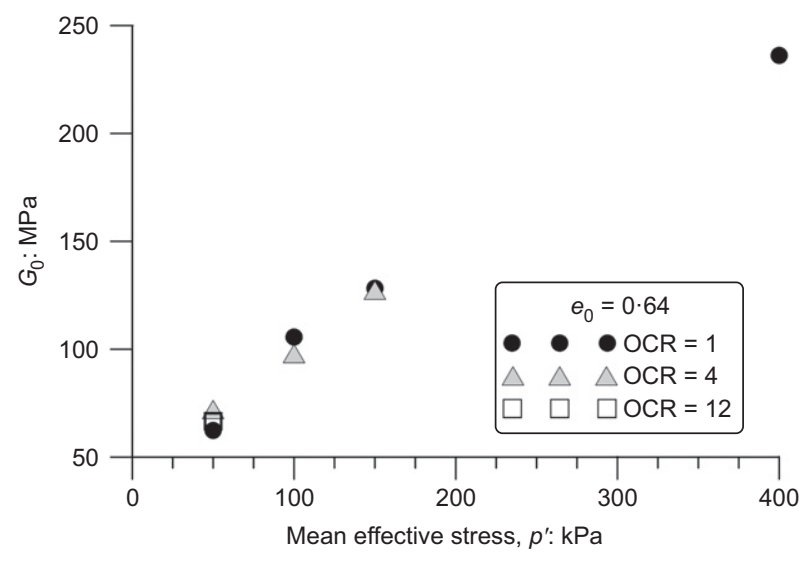

Fig. 13. Effect of OCR on $G_{0}$ for Dunkirk sand

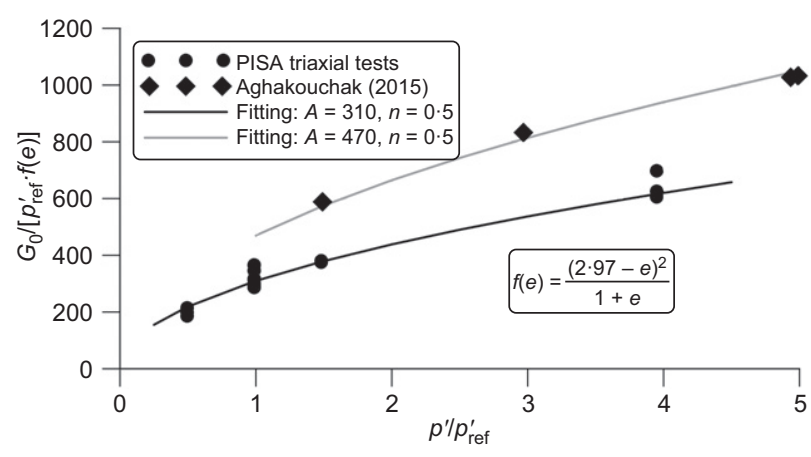

Fig. 14. Hardin \& Black (1968) approximation of $G_{0}$ for Dunkirk sand

Taborda et al., 2014) and implicitly assumes $n=0 \cdot 5$

$$
G_{0}=B p_{\text {ref }}^{\prime} f(e)\left(p^{\prime} / p_{\text {ref }}^{\prime}\right)^{0.5}
$$

where $f(e)=1 /\left(0 \cdot 3+0 \cdot 7 e^{2}\right)$. As seen in Fig. 15, this provides equally good fits to the elastic triaxial shear modulus measurements, indicating that $G_{0}$ can be approximated with expressions available in most constitutive models.

To estimate the $G_{0}$ profile with depth, use was made of the historic CPT and SCPT field data from Chow (1997) and of the two new SCPT traces (Fig. 16). The new $G_{0}$ laboratory trends represented by equations (1) and (2) are also plotted, adopting the parameters for $K_{0}$ consolidated samples ( $A=470$ and $n=0.5$; or $B=940$ ), as these are more appropriate for the in situ stress states. The calculated profiles plot very close to each other and agree well with the new SCPT-interpreted profiles over the top $10 \mathrm{~m}$. As noted above, the marked difference between Chow (1997) and the new $G_{0}$

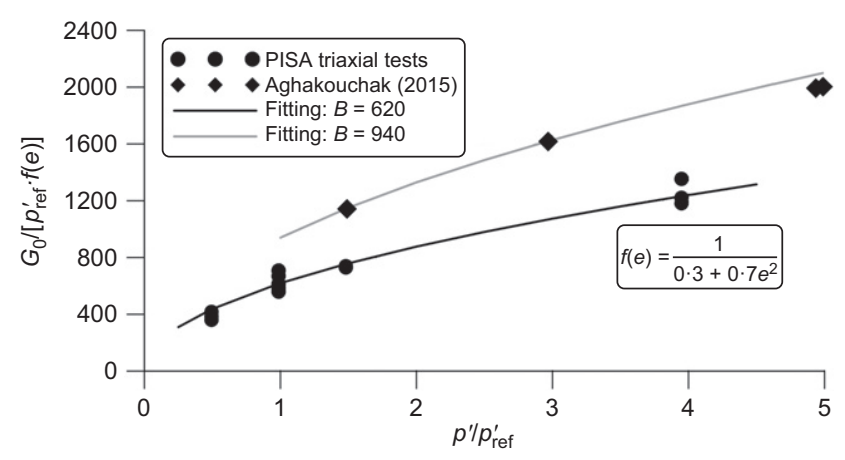

Fig. 15. Hardin (1978) approximation of $G_{0}$ for Dunkirk sand

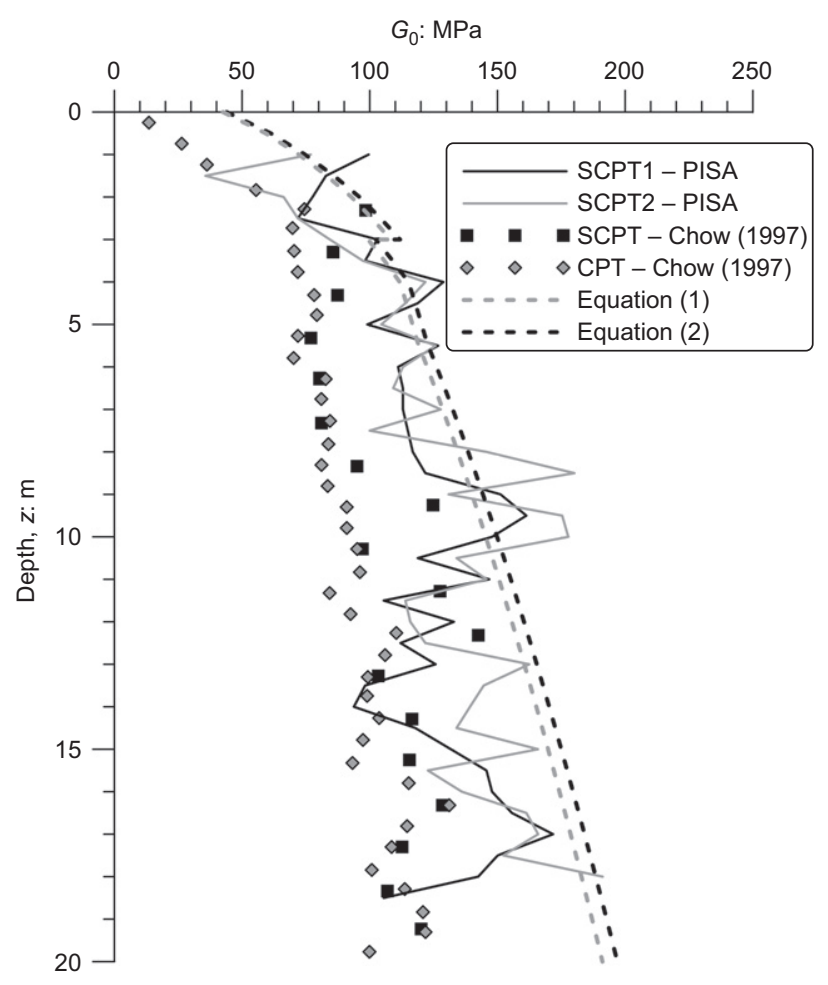

Fig. 16. $G_{0}$ profile at Dunkirk

profiles could be attributed to local site differences and/or ageing under the hydraulic fill.

Interpretation of critical state strength. To estimate the strength at critical state, the variations of stress ratio $q / p^{\prime}$ with axial strain are analysed in Fig. 17. Clearly, for initially dense samples, critical states can only be reached at high deformation levels, rendering their identification a difficult process. However, as shown in Fig. 17, the new triaxial testing involved shear strains in excess of $25 \%$ in compression and $10 \%$ in extension, enabling the ultimate (critical state) stress ratios $M_{\mathrm{cs}}^{\mathrm{c}}=1.28$ and $M_{\mathrm{cs}}^{\mathrm{e}}=0.92$ in compression and extension, respectively, to be estimated, corresponding to $\phi_{\mathrm{TXC}}^{\prime}=32^{\circ}$ and $\phi_{\mathrm{TXE}}^{\prime}=33^{\circ}$, respectively. Such similarities in $\phi^{\prime}$ have been shown with other pluviated sands (e.g. Vaid et al., 1990; Lade, 2006; Azeiteiro et al., 2017), while the ratio $M_{\mathrm{cs}}^{\mathrm{e}} / M_{\mathrm{cs}}^{\mathrm{c}}=0.718$ is within the typical range for silica sands of 0.67-0.75 (Loukidis \& Salgado, 2009).

To assess the position of the critical state line (CSL) in $e-p^{\prime}$ space, the new triaxial compression tests on samples with an

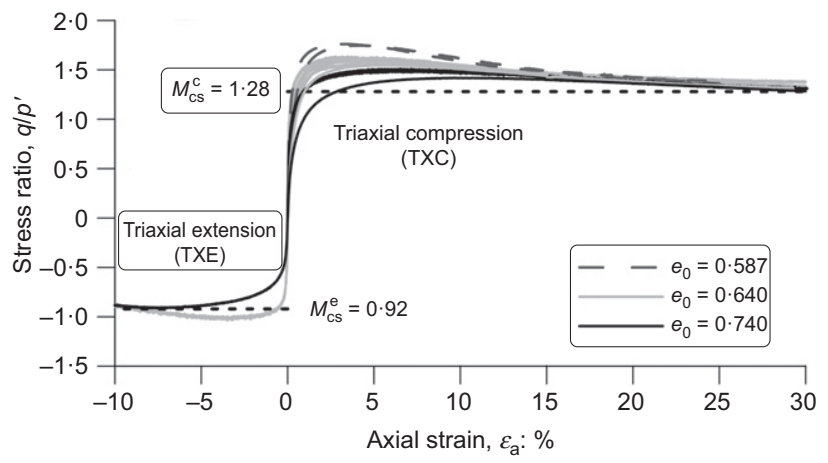

Fig. 17. Normalised stress-strain curves from the shearing stages of Dunkirk sand samples 
initial void ratio $e_{0}=0.64$ are plotted in Fig. 18, together with the estimate of critical stress states reported by Aghakouchak (2015) from his three compression tests with the same initial void ratio. The new tests sheared from $p^{\prime}$ of $150 \mathrm{kPa}$ and $400 \mathrm{kPa}$ dilate and reach critical state conditions that are in agreement with Aghakouchak (2015) estimates, while shearing from lower stress levels (50 to $100 \mathrm{kPa}$ ) stops short of reaching this range. This is usually attributed to the incompleteness of tests (Klotz \& Coop, 2002), due to premature strain localisation when shearing samples at lower stresses, and is one of the principal challenges in establishing the shape and position of the CSL in granular materials.

The CSL for sands has long been recognised as non-linear in the $e-\log p^{\prime}$ space and is often represented by the power law expression of Li \& Wang (1998)

$$
e_{\mathrm{cs}}=e_{0, \mathrm{ref}}-\lambda\left(\frac{p^{\prime}}{p_{\mathrm{ref}}^{\prime}}\right)^{\xi}
$$

where $e_{0, \text { ref }}, \lambda$ and $\xi$ are fitting parameters which can be estimated using the least-squares method. As proposed by Riemer et al. (1990), and assumed in other studies (e.g. Klotz \& Coop, 2002; Murthy et al., 2007), it is reasonable to expect that under zero effective stress the critical state would occur at a void ratio, $e_{0, \text { ref, }}$ similar to $e_{\max }$, which in the present case is 0.91 . The remaining two parameters, $\lambda$ and $\xi$, are calculated as $0 \cdot 135$ and $0 \cdot 179$, respectively (see Fig. 18), with $p_{\text {ref }}^{\prime}=101 \cdot 3 \mathrm{kPa}$ as before.

The additional testing of looser samples, with $e_{0}$ of around $0 \cdot 74$, was aimed at confirming critical states over the same stress range, as such samples should reach critical states under less volumetric dilation. However, they translated the CSL position by $\Delta e$ of about $0 \cdot 04$, highlighting again the challenges with sands of identifying the CSL in the $e-\ln p^{\prime}$ plane. Equation (3) fitting parameters for the new data were $0 \cdot 105$ and $0 \cdot 19$ for $\lambda$ and $\xi$, respectively.

Ideally, as pointed out by Jefferies \& Been (2006), samples prepared to very low relative densities $(<30 \%)$, consolidated to reasonably high mean effective stress levels, should be used to identify the location of the CSL. Indeed, under such conditions, the initial state lies above the CSL in $e-\ln p^{\prime}$ space and the sample should therefore approach the CSL without dilating, rendering the test interpretation simpler due to the absence of shear banding and strain localisation. However,

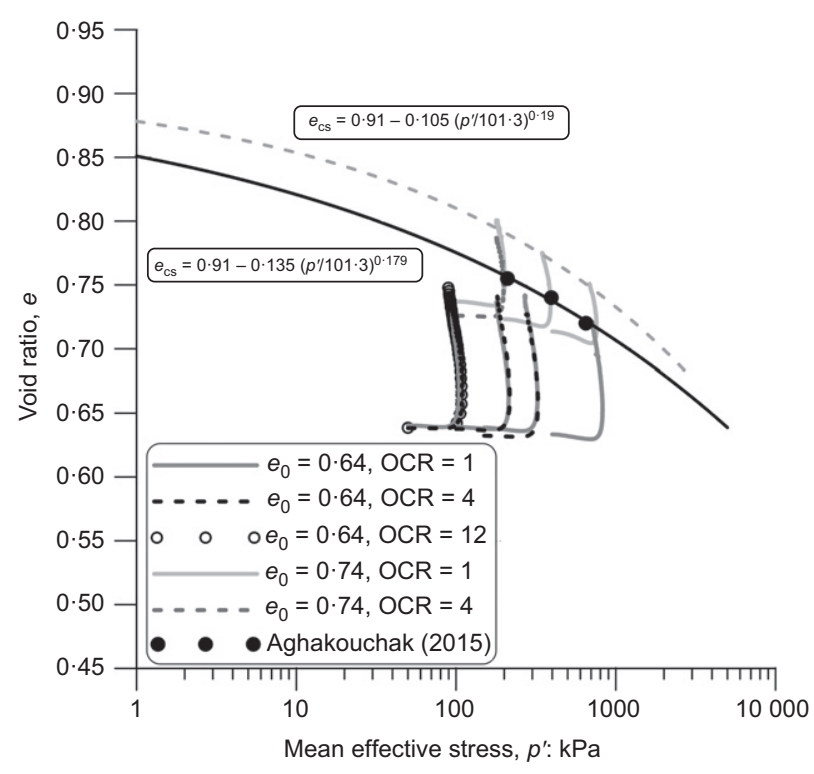

Fig. 18. Derivation of critical state line (CSL) for Dunkirk sand this approach could not be adopted in the present study as the necessary relative densities could not be achieved by water pluviation and the experimental programme needed to focus on characterising samples subjected to initial conditions representative of those found in the field.

Interpretation of peak strength and phase transformation states. The critical state frameworks for modelling the behaviour of sands adopt the state parameter, $\psi\left(=e-e_{\mathrm{cs}}\right)$, of Been \& Jefferies (1985) to describe the current state of the soil with respect to its critical state. When discussing the peak stress ratio, $\eta_{\text {peak }}\left(=(q / p)_{\text {peak }}\right)$, exhibited by denserthan-critical samples (i.e. $\psi<0$ ), Wood et al. (1994) showed that it can be related to the associated value of the state parameter, $\psi_{\text {peak }}\left(=e_{\text {peak }}-e_{\mathrm{cs}}\right)$, with the following expression

$$
\eta_{\text {peak }}^{\mathrm{c}, \mathrm{e}}=M_{\mathrm{cs}}^{\mathrm{c}, \mathrm{e}}-k_{\text {peak }}^{\mathrm{c}, \mathrm{e}} \psi_{\text {peak }}
$$

where $k_{\text {peak }}^{c, e}$ is a material constant that is different in triaxial compression and extension. However, given that most databases of sand behaviour are composed of tests carried out under triaxial compression, it is often assumed that, in extension, $k_{\text {peak }}^{\mathrm{e}}=k_{\text {peak }}^{\mathrm{c}} M_{\mathrm{cs}}^{\mathrm{e}} / M_{\mathrm{cs}}^{\mathrm{c}}$. This simplification, along with the linear relationship presented in equation (4), has been adopted in a number of constitutive models, particularly those based on that proposed by Manzari \& Dafalias (1997). More recently, however, Azeiteiro et al. (2017) have shown that the above $k_{\text {peak }}^{\mathrm{e}}$ assumption does not agree well with experiments on Hostun sand, suggesting that further research is needed.

Figure 19 plots $\left(\eta_{\text {peak }}^{\mathrm{c}}-M_{\mathrm{cs}}^{\mathrm{c}}\right)$ against $\psi_{\text {peak }}$ for all the compression tests, estimated using the lowest of the two CSLs in Fig. 18. Applying linear regression and specifying that the peak stress ratio must coincide with the critical state condition for $\psi=0$, the value of $k_{\text {peak }}^{\mathrm{c}}=3 \cdot 30$ is derived. Despite being within the range of values suggested by Papadimitriou \& Bouckovalas (2002) - that is, $0 \cdot 5$ to $4.0-$ this value is slightly larger than those calibrated for other sands, such as 1.92 for Leighton Buzzard fraction-E sand (Taborda, 2011), 2.18 for Nevada sand (Taborda et al., 2014), 2.50 for Fraser River sand (Klokidi, 2015; Tsaparli et al., 2016) and $2 \cdot 81$ for Hostun sand (Azeiteiro et al., 2017). However, it should also be noted that considerable variation in the value of this constant exists, with Papadimitriou \& Bouckovalas (2002) and Manzari \& Dafalias (1997) proposing 1.45 and 3.975, respectively, for Nevada sand.

A similar approach is applied for the phase transformation state, which is defined by the transition from plastic

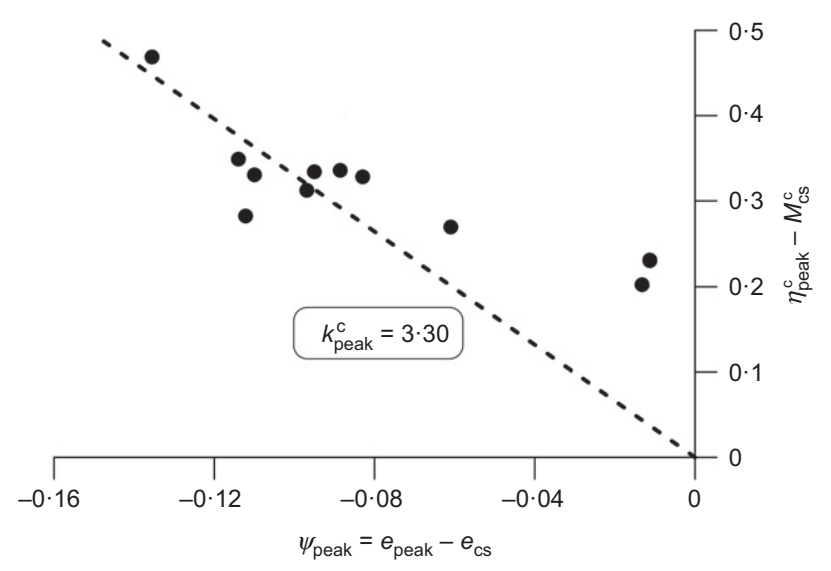

Fig. 19. Evaluation of peak stress ratio state for Dunkirk sand samples in compression 
contraction to plastic dilation. While the occurrence of the phase transformation state is easily recognisable in undrained tests, as it corresponds to the minimum mobilised $p^{\prime}$ (Ishihara et al., 1975), identifying the phase transformation state from a drained test requires the isolation and identification of the plastic strains. Consequently, the occurrence of the phase transformation state is associated with the stress ratio, $\eta_{\mathrm{PT}}$, at which the plastic dilatancy ratio, $D^{\mathrm{pl}}$, changes sign

$$
D^{\mathrm{pl}}=\frac{\Delta \varepsilon_{\mathrm{vol}}^{\mathrm{pl}}}{\Delta E_{\mathrm{d}}^{\mathrm{pl}}}=\frac{\Delta \varepsilon_{\mathrm{vol}}-\Delta \varepsilon_{\mathrm{vol}}^{\mathrm{el}}}{\Delta E_{\mathrm{d}}-\Delta E_{\mathrm{d}}^{\mathrm{el}}}=\frac{\Delta \varepsilon_{\mathrm{vol}}-\Delta p^{\prime} / K_{\mathrm{tan}}}{\Delta E_{\mathrm{d}}-\Delta q / 3 G_{\mathrm{tan}}}
$$

The drained test approach introduces a greater degree of uncertainty as it depends on the assumptions made regarding elastic behaviour, which is both non-linear and pressure dependent. Moreover, for denser-than-critical samples, such as those investigated here, phase transformation tends to occur at relatively small stress ratios, and consequently at very small deformations, rendering the separation of elastic and plastic strains particularly difficult.

Similar to the description of the peak stress ratio state in equation (4), Manzari \& Dafalias (1997) proposed a relationship between the stress ratio at phase transformation, $\eta_{\mathrm{PT}}$, and the current value of the state parameter

$$
\eta_{\mathrm{PT}}^{\mathrm{c}, \mathrm{e}}=M_{\mathrm{cs}}^{\mathrm{c}, \mathrm{e}}+k_{\mathrm{PT}}^{\mathrm{c}, \mathrm{e}} \psi_{\mathrm{PT}}
$$

where $k_{\mathrm{PT}}^{\mathrm{c}}$ e is a material constant, having different values again for compression and extension, although the simplification $k_{\mathrm{PT}}^{\mathrm{e}}=k_{\mathrm{PT}}^{\mathrm{c}} M_{\mathrm{cs}}^{\mathrm{e}} / M_{\mathrm{cs}}^{\mathrm{c}}$ is often adopted for modelling.

Assuming that the elastic shear modulus depends only on mean effective stress, as detailed earlier, and that this material is characterised by a Poisson ratio of $0 \cdot 17$ (Kuwano, 1999), the occurrence of the phase transformation state for all compression tests was estimated. These are presented in Fig. 20, which plots $\left(\eta_{\mathrm{PT}}^{\mathrm{c}}-M_{\mathrm{cs}}^{\mathrm{c}}\right)$ against $\psi_{\mathrm{PT}}\left(=e_{\mathrm{PT}}-e_{\mathrm{cs}}\right)$. Given that at critical state the plastic dilatancy rate must be zero, a linear regression ensuring that $\eta_{\mathrm{PT}}^{\mathrm{c}}=M_{\mathrm{cs}}^{\mathrm{c}}$ for $\psi=0$ was performed, yielding a value of $k_{\mathrm{PT}}^{\mathrm{c}}=0 \cdot 88$. This value is clearly within the range proposed by Papadimitriou \& Bouckovalas (2002) - that is, $0 \cdot 1-3 \cdot 0$ - and agrees well with values reported for other materials, such as 0.94 for Hostun sand (Azeiteiro et al., 2017), 1.80 for Fraser River sand (Klokidi, 2015; Tsaparli et al., 2016), 2.14 for Leighton Buzzard fraction-E sand (Taborda, 2011) and 2.35 for Nevada sand (Taborda et al., 2014). As before, the uncertainties in the evaluation of this parameter are particularly evident for the case of Nevada sand where values of $k_{\mathrm{PT}}^{\mathrm{c}}$ of 0.30 and 4.20 have been reported by

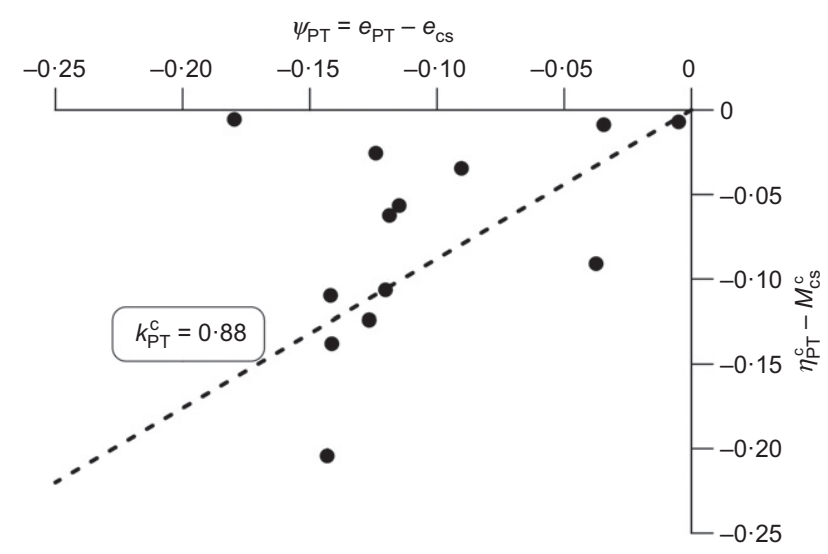

Fig. 20. Evaluation of phase transformation state for Dunkirk sand samples in compression
Papadimitriou \& Bouckovalas (2002) and Manzari \& Dafalias (1997), respectively.

\section{CONCLUSIONS}

The paper provides an overview of the geotechnical characterisation for the Cowden (stiff glacial clay) and Dunkirk (dense sand) sites adopted for the large-scale field testing programme under the PISA monopile JIP research project. This characterisation was essential to the design of the monopile experiments (Byrne et al., 2019; McAdam et al., 2019) and the development of FE analyses of these experiments (Taborda et al., 2019; Zdravković et al., 2019) in the sites' quite different geotechnical profiles.

New field CPTu and SCPT testing, sampling and laboratory experimentation were undertaken and combined with historical studies. The synthesis presented above covered index properties, compressibility, non-linear stiffness and ultimate conditions of the soils at the two sites. The key conclusions drawn from the reported characterisation work are listed below.

(a) The new investigations at both Cowden and Dunkirk indicated geotechnical profiles for the PISA locations that differed in important ways from those established in earlier studies. In particular, the shallower section at Cowden displayed noticeably lower undrained shear strength, while the Dunkirk profile indicated higher CPT resistances and shear stiffnesses, along with a lower groundwater table.

(b) The Cowden till contains a significant fraction of stony material that made rotary coring and triaxial specimen preparation difficult and led to spiky $\mathrm{CPTu}$ profiles.

(c) Perhaps surprisingly, the stone content and fissuring noted at shallow depths at Cowden did not lead to any marked difference between the outcomes of triaxial tests on 38 and $100 \mathrm{~mm}$ dia. specimens.

(d) The Geobore-S rotary core sampling at Cowden showed negligible sample disturbance and scatter in experimental results, compared to pushed-in sampling applied in previous studies.

(e) High-pressure CRS oedometer tests on natural and reconstituted samples of Cowden till indicated that the finer matrix material has a stable natural structure that does not collapse under loading to high effective stress levels.

( $f$ ) High-quality information was gained on the two sites' stiffness characteristics, showing how the shear modulus profiles varied between laboratory and field measurements.

(g) The compressibility and larger strain shear behaviours of the soils present at Cowden and Dunkirk fit well with the critical state interpretative framework. The sand and till specimens all tended towards critical states after shearing to large strains. Neither geomaterial was overly affected by shear bifurcation under triaxial compression testing.

(h) Despite some scatter in the Dunkirk data, the interpreted peak stress ratio and phase transformation states correlate well with the state parameter and agree with silica sand trends reported in the literature.

More generally, the paper outlines the approach for characterising soil behaviour in complex engineering applications involving advanced numerical analyses. Evaluating different, potentially disparate sources of field and laboratory experimental evidence is key to developing a sound engineering 


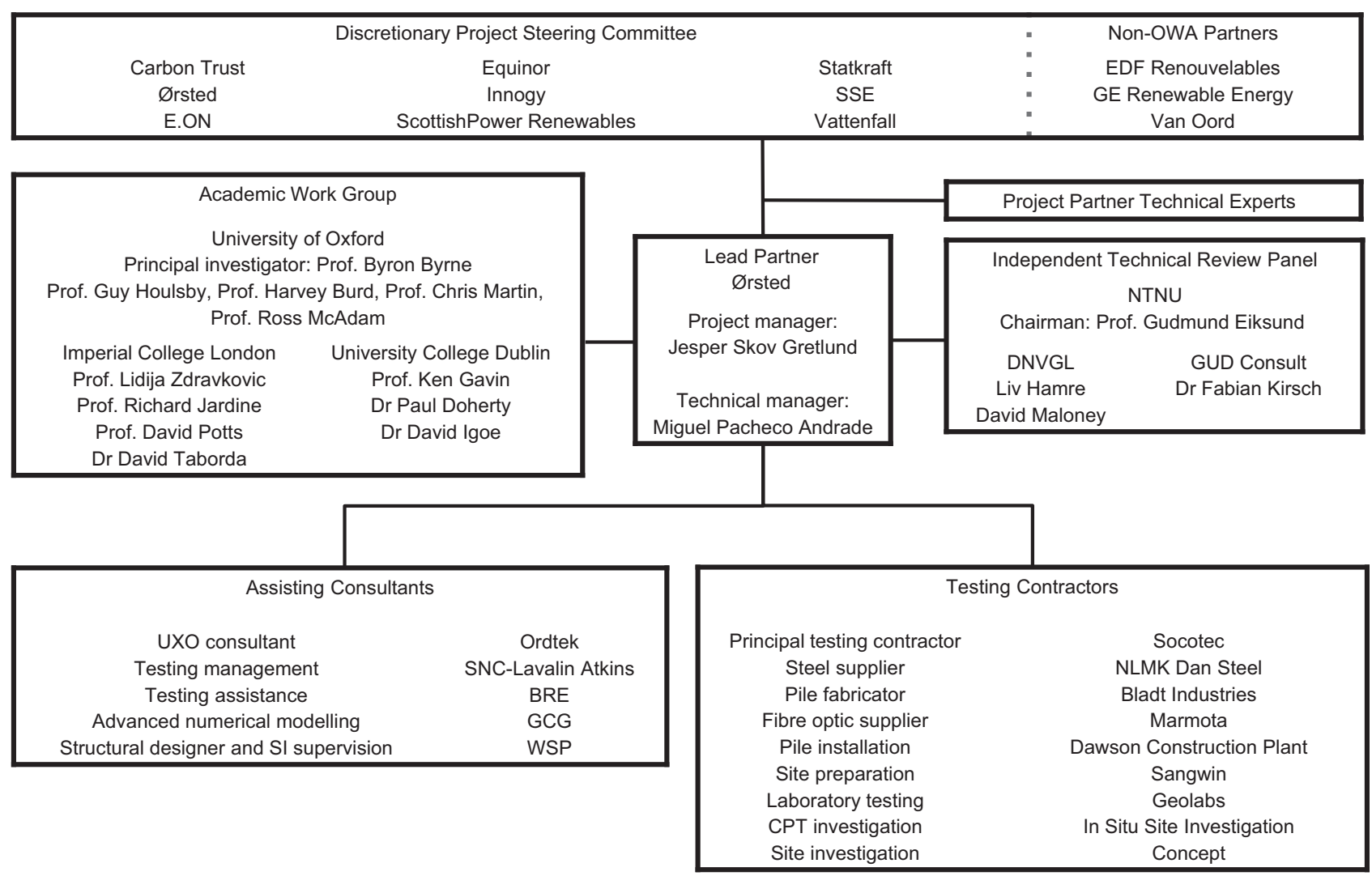

Fig. 21. Organisation chart of the PISA project

interpretation, as is the application of cross-checking and critical engineering judgement. The presented characterisation approach is required to apply the fully site-specific option in the PISA monopile design methodology, which will be developed in subsequent publications.

\section{ACKNOWLEDGEMENTS}

The PISA project was funded by the UK Department for Energy and Climate Change (DECC) and the PISA industry partners under the umbrella of the offshore wind accelerator (OWA) programme, which was designed and is led by the Carbon Trust. The authors acknowledge the provision of financial and technical support by the following project partners: Ørsted Wind Power (formerly DONG Energy), Alstom Wind, E.ON, EDF, Equinor (formerly Statoil), innogy, SPR, SSE, Vattenfall and Van Oord. The authors acknowledge gratefully the work of Socotec UK Ltd (formerly ESG) as the main contractor for the design and execution of the field testing programme.

\section{APPENDIX. ORGANISATIONAL STRUCTURE \\ OF THE PISA PROJECT}

Figure 21 depicts the organisation chart of the PISA project. The Academic Work Group (AWG) planned and carried out all strands of research, in close collaboration with Ørsted (formerly DONG Energy) as the lead industry partner who provided input on behalf of other industry partners. The project established an Independent Technical Review Panel (ITRP), which involved other academic institutions and a certifying body DNV-GL. The ITRP reviewed all of the AWG's project outputs and provided feedback at regular meetings and workshops. A number of sub-contractors were engaged at appropriate stages of the project, from initial numerical analyses and site investigation, to steel supply and pile fabrication, and finally pile installation and testing. Overall, nearly 100 people have been involved with the project over the period of its duration.

\section{NOTATION}

$A$ fitting parameter in equation (1)

$B$ fitting parameter in equation (2)

$C_{\mathrm{c}} \quad$ compressibility coefficient

$C_{\mathrm{s}}$ swelling coefficient

$D^{\mathrm{pl}} \quad$ plastic dilatancy ratio in equation (5)

$D_{\mathrm{R}}$ relative density

$e$ void ratio

$e_{0}$ initial void ratio

$e_{0, \text { ref }}$ reference void ratio in equation (3)

$e_{\mathrm{cs}}$ void ratio at critical state

$e_{\max }$ maximum void ratio

$e_{\min }$ minimum void ratio

$f(e)$ void ratio function

$G_{0} \quad$ elastic shear modulus

$G_{\mathrm{hh}}$ horizontal component of shear modulus

$G_{\text {sec }}$ secant shear modulus

$G_{\text {tan }}$ tangent shear modulus

$G_{\mathrm{vh}} \quad$ vertical component of shear modulus

$K_{0} \quad$ earth pressure coefficient at rest

$K_{\tan }$ tangent bulk modulus

$k \quad$ soil permeability

$k_{\text {peak }}^{\mathrm{c}, \mathrm{e}}$ material constant in compression and extension, equation (4)

$m$ fitting parameter in equation (1)

$n$ fitting parameter in equation (1)

$p^{\prime}$ mean effective stress

$p_{\text {ref }}^{\prime}$ reference pressure

$q$ deviatoric stress

$S_{\mathrm{u}} \quad$ undrained shear strength

$S_{\mathrm{u}, \mathrm{TXC}}$ undrained shear strength in triaxial compression

$v$ specific volume

$z$ depth below ground surface

$\Delta E_{\mathrm{d}}$ increment of total deviatoric strain in equation (5)

$\Delta E_{\mathrm{d}}^{\mathrm{el}}$ increment of elastic deviatoric strain in equation (5)

$\Delta E_{\mathrm{d}}^{\mathrm{pl}} \quad$ increment of plastic deviatoric strain in equation (5)

$\Delta \varepsilon_{\mathrm{vol}}$ increment of total volumetric strain in equation (5)

$\Delta \varepsilon_{\mathrm{vol}}^{\mathrm{el}}$ increment of elastic volumetric strain in equation (5) 


\begin{tabular}{|c|c|}
\hline$\Delta \varepsilon_{\mathrm{vol}}^{\mathrm{pl}}$ & increment of plastic volumetric strain in equation (5) \\
\hline$E_{\mathrm{d}}$ & deviatoric strain \\
\hline$\varepsilon_{\mathrm{a}}$ & axial strain \\
\hline$\varepsilon_{\mathrm{r}}$ & radial strain \\
\hline & stress ratio $\left(q / p^{\prime}\right)$ \\
\hline$\eta_{\text {peak }}^{\mathrm{c}, \mathrm{e}}$ & peak stress ratio in compression or extension \\
\hline$\eta_{\mathrm{PT}}^{\mathrm{c}, \mathrm{e}}$ & $\begin{array}{l}\text { stress ratio at phase transformation in compression } \\
\text { or extension }\end{array}$ \\
\hline$\kappa$ & inclination of an isotropic swelling line \\
\hline$\lambda$ & $\begin{array}{l}\text { inclination of the isotropic normal compression line; } \\
\text { also, fitting parameter in equation ( } 3 \text { ) }\end{array}$ \\
\hline$M_{\mathrm{cs}}^{\mathrm{c}, \mathrm{e}}$ & critical state stress ratio in compression or extension \\
\hline & fitting parameter in equation (3) \\
\hline$\sigma_{\mathrm{v}}^{\prime}$ & vertical effective stress \\
\hline$\varphi_{\text {TXC }}^{\prime}$ & $\begin{array}{l}\text { critical state angle of shearing resistance in triaxial } \\
\text { compression }\end{array}$ \\
\hline$\varphi_{\text {TXE }}^{\prime}$ & $\begin{array}{l}\text { critical state angle of shearing resistance in triaxial } \\
\text { extension }\end{array}$ \\
\hline$\psi$ & state parameter \\
\hline$\psi_{\text {peak }}$ & state parameter at peak \\
\hline
\end{tabular}

\section{REFERENCES}

Ackerley, S. K., Standing, J. R. \& Kamal, R. H. (2016). A system for measuring local radial strains in triaxial apparatus. Géotechnique 66, No. 6, 515-522, https://doi.org/10.1680/ jgeot.15.T.027.

Aghakouchak, A. (2015). Advanced laboratory studies to explore the axial cyclic behaviour of driven piles. $\mathrm{PhD}$ thesis, Imperial College London, London, UK.

Alderlieste, E. A., Dijkstra, J. \& van Tol, A. F. (2011). Experimental investigation into pile diameter effects on laterally loaded mono-piles. In ASME 2011 30th international conference on ocean, offshore and arctic engineering, volume 7: CFD and VIV; offshore geotechnics, pp. 985-990, https://doi.org/10.1115/ OMAE2011-50068. New York, NY, USA: American Society of Mechanical Engineers.

Al Haj, K. (2014). Mechanical response of two plastic clay soils from Sudan. PhD thesis, Imperial College London, London, UK.

API (American Petroleum Institute) (2010). RP 1A-WSD recommended practice for planning, designing and constructing fixed offshore platforms. Washington, DC, USA: American Petroleum Institute.

Azeiteiro, R. J. N., Coelho, P. A. L. F., Taborda, D. M. G. \& Grazina, J. C. D. (2017). Critical state-based interpretation of the monotonic behaviour of Hostun sand. ASCE J. Geotech. Geoenviron. Engng 143, No. 5, https://doi.org/10.1061/(ASCE) GT.1943-5606.0001659.

Baldi, G., Bellotti, R., Ghionna, V., Jamiolkowski, M., Marchetti, S. \& Pasquelini, E. (1986). Flat dilatometer tests in calibration chambers. In Use of in situ tests in geotechnical engineering (ed. S. P. Clemence), Geotechnical Special Publication no. 6, pp. 431-446. New York, NY, USA: American Society of Civil Engineers.

Been, K. \& Jefferies, M. G. (1985). A state parameter for sands. Géotechnique 35, No. 2, 99-112, https://doi.org/10.1680/ geot.1985.35.2.99.

Brosse, A. (2012). Study of the anisotropy of three British mudrocks using a hollow cylinder apparatus. $\mathrm{PhD}$ thesis, Imperial College London, London, UK.

Brosse, A., Kamal, R. H., Jardine, R. J. \& Coop, M. R. (2017). The shear stiffness characteristics of four Eocene-to-Jurassic UK stiff clays. Géotechnique 67, No. 3, 242-259, https://doi.org/10.1680/ jgeot.15.P.236.

Brucy, F., Meunier, J. \& Nauroy, J. F. (1991). Behaviour of pile plug in sandy soils during and after driving. Proceedings of 23rd offshore technology conference, Houston, TX, USA, OTC 6514, pp. 145-154.

Burd, H. J., Beuckelaers, W. J. A. P., Byrne, B. W., Gavin, K. G., Houlsby, G. T., Igoe, D. J. P., Jardine, R. J., Martin, C. M., McAdam, R. A., Muir Wood, A., Potts, D. M., Skov Gretlund, J., Taborda, D. M. G. \& Zdravković, L. (2019). New data analysis methods for instrumented medium scale monopile field tests. Géotechnique, https://doi.org/10.1680/jgeot. 18.PISA.002.
Byrne, B. W., McAdam, R., Burd, H. J., Houlsby, G. T., Martin, C. M., Zdravkovic, L., Taborda, D. M. G., Potts, D. M., Jardine, R. J., Sideri, M., Schroeder, F. C., Gavin, K., Doherty, P., Igoe, D., Muir Wood, A., Kallehave, D. \& Skov Gretlund, J. (2015a). New design methods for large diameter piles under lateral loading for offshore wind applications. In Frontiers in offshore geotechnics III (ed. V. Meyer), pp. 705-710. Leiden, the Netherlands: CRC Press/ Balkema.

Byrne, B. W., McAdam, R. A., Burd, H. J., Houlsby, G. T., Martin, C. M., Gavin, K., Doherty, P., Igoe, D., Zdravkovic, L., Taborda, D. M. G., Potts, D. M., Jardine, R. J. Sideri, M., Schroeder, F. C., Muir Wood, A., Kallehave, D. \& Skov Gretlund, J. (2015b). Field testing of large diameter piles under lateral loading for offshore wind applications. In Geotechnical engineering for infrastructure and development: proceedings of the XVI European conference on soil mechanics and geotechnical engineering (eds M. G. Winter, D. M. Smith, P. J. L. Eldred and D. G. Toll), pp. 1255-1260. London, UK: ICE Publishing.

Byrne, B. W., McAdam, R. A., Burd, H. J., Houlsby, G. T., Martin, C. M., Beuckelaers, W. J. A. P., Zdravković, L., Taborda, D. M. G., Potts, D. M., Jardine, R. J., Ushev, E., Liu, T., Abadias, D., Gavin, K., Igoe, D., Doherty, P., Skov Gretlund, J., Pacheco Andrade, M., Muir Wood, A., Schroeder, F. C., Turner, S. \& Plummer, M. A. L. (2017). PISA: new design methods for offshore wind turbine monopiles. In Offshore site investigation and geotechnics: smarter solutions for future offshore developments, vol. 1, pp. 142-161. London, UK: Society for Underwater Technology.

Byrne, B. W., McAdam, R. A., Burd, H. J., Beuckelaers, W. J. A. P., Gavin, K. G., Houlsby, G. T., Igoe, D. J. P., Jardine, R. J., Martin, C. M., Muir Wood, A., Potts, D. M., Skov Gretlund, J., Taborda, D. M. G. \& Zdravković, L. (2019). Monotonic laterally loaded pile testing in a stiff glacial clay till at Cowden. Géotechnique, https://doi.org/10.1680/jgeot.18.PISA.003.

Chow, F. (1997). Investigations into the behaviour of displacement piles for offshore foundations. $\mathrm{PhD}$ thesis, Imperial College, University of London, London, UK.

Davidson, H. L. (1982). Laterally loaded drilled pier research, vol 1: design methodology, vol. 2: research documentation, Final Report. Washington, DC, USA: GAI Consultants Inc., for Electric Power Research Institute (EPRI), U.S. Department of Energy, Office of Scientific and Technical Information.

DNVGL (Det Norske Veritas-Germanischer Lloyd) (2016). DNVGL-ST-0126 - support structure for wind turbines. Oslo, Norway: Det Norske Veritas.

Doherty, P. \& Gavin, K. (2012). Laterally loaded monopile design for offshore wind farms. Proc. Instn Civ. Engrs - Energy 165, No. 1, 7-17, https://doi.org/10.1680/ener.11.00003.

Gasparre, A., Nishimura, S., Minh, N. A., Coop, M. R. \& Jardine, R. J. (2007). The stiffness of natural London Clay. Géotechnique 57, No. 1, 33-47, https://doi.org/10.1680/ geot.2007.57.1.33.

Gens, A. (1982). Stress-strain and strength characteristics of a low plasticity clay. $\mathrm{PhD}$ thesis, Imperial College, University of London, London, UK.

Gens, A. \& Hight, D. W. (1979). The laboratory measurement of design parameters for a glacial till. Proceedings of the 7th ECSMFE, Brighton, UK, vol. 2, pp. 57-65.

Gerolymos, N. \& Gazetas, G. (2006). Winkler model for lateral response of rigid caisson foundations in linear soil. Soil Dynamics Earthquake Engng 26, No. 5, 347-361.

Hardin, B. O. (1978). The nature of stress-strain behaviour for soils. In Earthquake engineering and soil dynamics - proceedings of the ASCE Geotechnical Engineering Division specialty conference, June 19-21, Pasadena, CA, USA, vol. 1, pp. 3-90. New York, NY, USA: American Society of Civil Engineers.

Hardin, B. O. \& Black, W. L. (1966). Sand stiffness under various triaxial stresses. J. Soil Mech. Found. Div. 92, No. SM 2, 27-42.

Hardin, B. O. \& Black, W. L. (1968). Vibration modulus of normally consolidated clay. J. Soil Mech. Found. Div. 94, No. SM 2, 353-369.

Hight, D. W. (1982). Laboratory investigations of sea-bed clays. $\mathrm{PhD}$ thesis, Imperial College, University of London, London, UK. 
Hosseini Kamal, R., Coop, M. R., Jardine, R. J. \& Brosse, A. (2014). The post-yield behaviour of four Eocene-to-Jurassic UK stiff clays. Géotechnique 64, No. 8, 620-634, https://doi.org/ 10.1680/geot.13.P.043.

Ishihara, K., Tatsuoka, F. \& Yasuda, S. (1975). Undrained deformation and liquefaction of sand under cyclic stresses. Soils Found. 15, No. 1, 29-44.

Jardine, R. J. (1985). Investigations of pile-soil behaviour, with special reference to the foundations of offshore structures. $\mathrm{PhD}$ thesis, Imperial College, University of London, London, UK.

Jardine, R. J. (1995). One perspective on the pre-failure deformation characteristics of some geomaterials. In Pre-failure deformation of geomaterials - proceedings of the international symposium, pp. 855-885. Rotterdam, the Netherlands: Balkema.

Jeanjean, P. (2009). Re-assessment of $p-y$ curves for soft clays from centrifuge testing and finite element modelling. Proceedings of the offshore technology conference, Houston, TX, USA, paper OTC 20158.

Jefferies, M. G. \& Been, K. (2006). Soil liquefaction: a critical state approach. London, UK: CRC Press.

Jovicic, V. \& Coop, M. R. (1997). Stiffness of coarse-grained soils at small strains. Géotechnique 47, No. 3, 545-561, https://doi.org/ 10.1680/geot.1997.47.3.545.

Kallehave, D., Byrne, B. W., Thilsted, C. L. \& Mikkelsen, K. K. (2015). Optimization of monopiles for offshore wind turbines. Phil. Trans. R. Soc. A 373, No. 2035, 20140100.

Klinkvort, R. T., Poder, M., Truong, P. \& Zania, V. (2016). Centrifuge modelling of rigid piles in soft clay. In Eurofuge 2016, 3rd European conference on physical modelling in geotechnics (eds L. Thorel, A. Bretschneider, M. Blanc and S. Escoffier). Paris, France: IFSTTAR.

Klokidi, M. (2015). Numerical simulation of liquefaction behaviour with focus on the re-liquefaction of sand deposits. MSc thesis, Imperial College London, London, UK.

Klotz, E. U. \& Coop, M. R. (2002). On the identification of critical state lines for sands. Geotech. Testing J. 25, No. 3, 289-302.

Kulhawy, F. H. \& Mayne, P. W. (1990). Manual on estimating soil properties for foundation design. Palo Alto, CA, USA: Electric Power Research Inst; Ithaca, NY, USA: Cornell University, Geotechnical Engineering Group.

Kuwano, R. (1999). The stiffness and yielding anisotropy of sand. $\mathrm{PhD}$ thesis, Imperial College, University of London, London, UK.

Kuwano, R. \& Jardine, R. J. (1998). Stiffness measurements in a stress path cell. In Prefailure behaviour of geomaterials (eds R. J. Jardine, M. C. R. Davies, D. W. Hight, A. K. C. Smith and S. E. Stallebrass), pp. 391-395. London, UK: Thomas Telford.

Kuwano, R. \& Jardine, R. J. (2002). On the applicability of cross-anisotropic elasticity to granular materials at very small strains. Géotechnique 52, No. 10, 727-749, https://doi.org/ 10.1680/geot.2002.52.10.727.

Lade, P. V. (2006). Assessment of test data for selection of 3-D failure criterion for sand. Int. J. Numer. Analyt. Methods Geomech. 30, No. 4, 307-333.

Lam, I. P. O. (2013). Diameter effect on $p-y$ curves. In Deep marine foundations - a perspective on the design and construction of deep marine foundations (eds R. A. Bittner and R. A. Ellman). Hawthorne, NJ, USA: Deep Foundations Institute.

Lam, I. P. O. \& Martin, G. R. (1986). Seismic design of high-way bridge foundations, Report No. FHWA/RD-86/102. Washington, DC, USA: Federal Highway Administration.

Lehane, B. (1992). Experimental investigations of pile behaviour using instrumented field piles. $\mathrm{PhD}$ thesis, Imperial College, University of London, London, UK.

Li, X. S. \& Wang, Y. (1998). Linear representation of steady-state line for sand. J. Geotech. Geoenviron. Engng 124, No. 12, 1215-1217.

Liu, T., Aghakouchak, A., Taborda, D. M. G. \& Jardine, R. J. (2017). Advanced laboratory characterization of a fine marine sand from Dunkirk, France. In Proceedings of the 19th international conference on soil mechanics and geotechnical engineering (ICSMGE 2017): unearth the future, connect beyond (eds W. Lee, J. S. Lee, H. K. Kim and D. S. Kim), pp. 457-460. Seoul, Republic of Korea: Korea Geotechnical Society.
Loukidis, D. \& Salgado, R. (2009). Modeling sand response using two-surface plasticity. Comput. Geotech.36, No. 1-2, 166-186.

Lunne, T. \& Christofferson, H. P. (1983). Cone penetrometer interpretation for offshore sands. Proceedings of the offshore technology conference, Houston, TX, USA, paper OTC4464, pp. $181-192$.

Manzari, M. T. \& Dafalias, Y. F. (1997). A critical state two-surface plasticity model for sands. Géotechnique 47, No. 2, 255-272, https://doi.org/10.1680/geot.1997.47.2.255.

McAdam, R. A., Byrne, B. W., Houlsby, G. T., Beuckelaers, W. J. A. P., Burd, H. J., Gavin, K. G., Igoe, D. J. P., Jardine, R. J., Martin, C. M., Muir Wood, A., Potts, D. M., Skov Gretlund, J., Taborda, D. M. G. \& Zdravković, L. (2019). Monotonic laterally loaded pile testing in a dense marine sand at Dunkirk. Géotechnique, https://doi. org/10.1680/jgeot.18.PISA.004.

Murthy, T. G., Loukidis, D., Carraro, J. A. H., Prezzi, M. \& Salgado, R. (2007). Undrained monotonic response of clean and silty sands. Géotechnique 57, No. 3, 273-288, https://doi.org/ 10.1680/geot.2007.57.3.273.

Papadimitriou, A. G. \& Bouckovalas, G. D. (2002). Plasticity model for sand under small and large cyclic strains: a multiaxial formulation. Soil Dynamics Earthquake Engng 22, No. 3, 191-204.

Powell, J. J. M. \& Butcher, A. P. (2003). Characterisation of a glacial till at Cowden, Humberside. In Characterisation and engineering properties of natural soils (eds T. S. Tan, K. K. Phoon, D. W. Hight and S. Leroueil), pp. 983-1020. Lisse, the Netherlands: A. A. Balkema, Swets \& Zeitlinger.

Powell, J. J. M. \& Quarterman, R. S. T. (1988). The interpretation of cone penetration tests in clays, with particular reference to rate effects. In Penetration testing, 1988: proceedings of the first international symposium on penetration testing, ISOPT-1 (ed. J. de Ruiter), vol. 2, pp. 903-909. Rotterdam, the Netherlands: Balkema.

Riemer, M. F., Seed, R. B., Nicholson, P. G. \& Jong, H. L. (1990). Steady state testing of loose sands: limiting minimum density. J. Geotech. Engng 116, No. 2, 332-337.

Robson, R. (1988). Review of laboratory and field data from the Cowden test site, Holderness. MSc thesis, Imperial College, University of London, London, UK.

Sim, W. W., Aghakouchak, A. \& Jardine, R. J. (2013). Cyclic triaxial tests to aid offshore pile analysis and design. Proc. Instn Civ. Engrs - Geotech. Engng 166, No. 2, 111-121, https://doi.org/ 10.1680/geng. 12.00056.

Taborda, D. M. G. (2011). Development of constitutive models for application in soil dynamics. $\mathrm{PhD}$ thesis, Imperial College, University of London, London, UK.

Taborda, D. M. G., Zdravković, L., Kontoe, S. \& Potts, D. M (2014). Computational study on the modification of a bounding surface plasticity model for sands. Comput. Geotech. 59, 145-160.

Taborda, D. M. G., Zdravković, L., Potts, D. M., Burd, H. J., Byrne, B. W., Gavin, K. G., Houlsby, G. T., Jardine, R. J., Liu, T., Martin, C. M. \& McAdam, R. A. (2019). Finite element modelling of laterally loaded piles in a dense marine sand at Dunkirk. Géotechnique, https://doi.org/10.1680/jgeot. 18.PISA.006.

Tsaparli, V., Kontoe, S., Taborda, D. M. G. \& Potts, D. M. (2016). Vertical ground motion and its effects on liquefaction resistance of fully saturated sand deposits. Proc. R. Soc. A: Math., Phys. Engng Sci. 472, No. 2192, article 20160434, https://doi.org/ 10.1098/rspa.2016.0434.

Ushev, E., Jardine, R. J. \& Liu, T. (2015). Interim report on soil testing for PISA project on samples taken at Cowden site 2014-2015, Internal Report. London, UK: Imperial College London.

Vaid, Y. P., Chung, E. K. F. \& Kuerbis, R. H. (1990). Stress path and steady state. Can. Geotech. J. 27, No. 1, 1-7.

Vaughan, P. R. (1994). Assumption, prediction and reality in geotechnical engineering. Géotechnique 44, No. 4, 573-609, https://doi.org/10.1680/geot.1994.44.4.573.

Viggiani, G. \& Atkinson, J. H. (1995). Stiffness of fine-grained soil at very small strains. Géotechnique 45, No. 2, 249-265, https://doi.org/10.1680/geot.1995.45.2.249.

Wood, D. M., Belkheir, K. \& Liu, D. F. (1994). Strain-softening and state parameter for sand modelling. 
Géotechnique 44, No. 2, 335-339, https://doi.org/10.1680/ geot.1994.44.2.335.

Zdravkovic, L., Taborda, D. M. G., Potts, D. M., Jardine, R. J., Sideri, M., Schroeder, F. C., Byrne, B. W., McAdam, R., Burd, H. J., Houlsby, G. T., Martin, C. M., Gavin, K., Doherty, P., Igoe, D., Muir Wood, A., Kallehave, D. \& Skov Gretlund, J. (2015). Numerical modelling of large diameter piles under lateral loading. In Frontiers in offshore geotechnics III (ed. V. Meyer), pp. 759-764. Leiden, the Netherlands: CRC Press/Balkema.
Zdravković, L., Taborda, D. M. G., Potts, D. M., Abadias, D., Burd, H. J., Byrne, B. W., Gavin, K. G., Houlsby, G. T., Jardine, R. J., Martin, C. M., McAdam, R. A. \& Ushev, E. (2019). Finite element modelling of laterally loaded piles in a stiff glacial clay till at Cowden. Géotechnique, https://doi.org/ 10.1680/jgeot.18.PISA.005.

Zhou, Y. G. \& Chen, Y. M. (2005). Influence of seismic cyclic loading history on small strain shear modulus of saturated sands. Soil Dynamics Earthquake Engng 25, No. 5, $341-353$. 